\title{
Cocaine Directly Inhibits a6- Containing Nicotinic Acetylcholine Receptors in Human SH-EP1 Cells and Mouse VTA DA Neurons
}

Dejie Chen ${ }^{1,2 \dagger}$, Fenfei Gao ${ }^{3 \dagger}$, Xiaokuang $\mathrm{Ma}^{2,3}$, Jason Brek Eaton', Yuanbing Huang, Ming $\mathrm{Gao}^{2}$, Yongchang Chang ${ }^{2}$, Zegang $\mathrm{Ma}^{4}$, Taleen Der-Ghazarian ${ }^{5}$, Janet Neisewander ${ }^{5}$, Paul Whiteaker ${ }^{2}$, Jie Wu ${ }^{1,2,3 *}$ and Quanxi Su${ }^{1 *}$

'Department of Neurology, Yunfu People's Hospital, Yunfu, China, ${ }^{2}$ Division of Neurobiology, Barrow Neurological Institute, St. Joseph's Hospital and Medical Center, Phoenix, AZ, United States, ${ }^{3}$ Department of Pharmacology,

OPEN ACCESS

Edited by:

Tod Edward Kippin

University of California,

Santa Barbara, United States

Reviewed by:

Erik B. Oleson,

University of Colorado Denver,

United States

Kathryn J. Reissner,

University of North Carolina at

Chapel Hill, United States

*Correspondence:

Jie Wu

jiewubni@gmail.com;

jie.wu@dignityhealth.org

Quanxi Su

suquanxi@163.com

tThese authors have contributed equally to this work

Specialty section:

This article was submitted to

Neuropharmacology,

a section of the journal

Frontiers in Pharmacology

Received: 06 October 2018 Accepted: 21 January 2019

Published: 14 February 2019

Citation:

Chen D, Gao F, MaX, Eaton JB, Huang $Y$, Gao M, Chang Y, Ma Z, Der-Ghazarian T, Neisewander J, Whiteaker P, Wu J and Su Q (2019)

Cocaine Directly Inhibits $\alpha 6$-Containing Nicotinic Acetylcholine

Receptors in Human SH-EP1 Cells and Mouse VTA DA Neurons.

Front. Pharmacol. 10:72. doi: 10.3389/fphar.2019.00072
Shantou University Medical College, Shantou, China, ${ }^{4}$ Department of Physiology, Qingdao University of Medical College, Qingdao, China, ${ }^{5}$ School of Life Sciences, Arizona State University, Tempe, AZ, United States

Alpha6-containing nicotinic acetylcholine receptors are primarily found in neurons of the midbrain dopaminergic (DA) system, suggesting these receptors are potentially involved in drug reward and dependence. Here, we report a novel effect that cocaine directly inhibits $\alpha 6 \mathrm{~N} / \alpha 3 \mathrm{C} \beta 2 \beta 3-n A C h R\left(\alpha 6^{*}-n A C h R s\right)$ function. Human $\alpha 6^{*}-n A C h R s$ were heterologously expressed within cells of the $\mathrm{SH}-\mathrm{EP} 1$ cell line for functional characterization. Mechanically dissociated DA neurons from mouse ventral tegmental area (VTA) were used as a model of presynaptic $\alpha 6^{*}$-nAChR activation since this method preserves terminal boutons. Patch-clamp recordings in whole-cell configuration were used to measure $\alpha 6^{*}-n A C h R$ function as well as evaluate the effects of cocaine. In SH-EP1 cells containing heterologously expressed human $\alpha 6^{*}$-nAChRs, cocaine inhibits nicotineinduced inward currents in a concentration-dependent manner with an $\mathrm{IC}_{50}$ value of $30 \mu \mathrm{M}$. Interestingly, in the presence of $30 \mu \mathrm{M}$ cocaine, the maximal current response of the nicotine concentration-response curve is reduced without changing nicotine's $\mathrm{EC}_{50}$ value, suggesting a noncompetitive mechanism. Furthermore, analysis of wholecell current kinetics demonstrated that cocaine slows nAChR channel activation but accelerates whole-cell current decay time. Our findings demonstrate that cocaineinduced inhibition occurs solely with bath application, but not during intracellular administration, and this inhibition is not use-dependent. Additionally, in Xenopus oocytes, cocaine inhibits both $\alpha 6 \mathrm{~N} / \alpha 3 \mathrm{C} \beta 2 \beta 3-\mathrm{nAChRs}$ and $\alpha 6 \mathrm{M} 211 \mathrm{~L} / \alpha 3 \mathrm{IC} \beta 2 \beta 3-\mathrm{nCAhRs}$ similarly, suggesting that cocaine may not act on the $\alpha 3$ transmembrane domain of chimeric $\alpha 6 \mathrm{~N} / \alpha 3 \mathrm{C} \beta 2 \beta 3-\mathrm{nAChR}$. In mechanically isolated VTA DA neurons, cocaine abolishes $\alpha 6^{\star}$-nAChR-mediated enhancement of spontaneous inhibitory postsynaptic currents (sIPSCs). Collectively, these studies provide the first evidence that cocaine directly inhibits the function of both heterologously and naturally expressed $\alpha 6^{*}$-nAChRs. These findings suggest that $\alpha 6^{*}$-nAChRs may provide a novel pharmacological target mediating the effects of cocaine and may underlie a novel mechanism of cocaine reward and dependence.

Keywords: cocaine, nicotinic acetylcholine receptor, SH-EP1 cells, VTA, dopamine neurons, patch clamp 


\section{INTRODUCTION}

Cocaine is a widely used psychostimulant drug, and its abuse is associated with multiple physical and psychiatric sequelae. Cocaine addiction is a serious public health problem worldwide, leading to alterations in memory, behavior, and neuronal physiology. The first clinical signs of cocaine toxicity are typically palpitations, epistaxis, sweating, headache, anxiety, tremors, muscle spasm, and hyperventilation (Nnadi et al., 2005). In humans, neuropsychiatric complications are evident in approximately $60 \%$ of cocaine users including depression, suicidal ideation, paranoia, kleptomania, and catatonia. Cocaine use disorder also leads to a series of neurological disorders such as seizures, optic neuropathy, cerebral infarction, subarachnoid and intracerebral hemorrhage, multifocal cerebral ischemia, and cerebral atrophy, as well as cardiac dysfunction including myocardial infarction triggering global brain ischemia and edema (Moorman et al., 2013; Bodmer et al., 2014; Cagienard et al., 2014; Sharma et al., 2014; Sordo et al., 2014). Despite this broad foundation of clinical knowledge, the detailed mechanisms underlying cocaine-induced effects in the brain remain largely unknown.

Previous investigations have established that cocaine increases inter-synaptic dopamine levels through inhibition of dopamine transporters, which produces its rewarding effect (Ritz et al., 1987; Jones et al., 1995); however, cocaine also acts on other targets and influences midbrain dopamine (DA) neuronal activity and DA release. For example, in vivo electrophysiological recordings showed that acute intravenous administration of cocaine caused a significant, dose-dependent, partial inhibition (50-70\%) of the firing of antidromically identified mesoaccumbens DA neurons, and both somatodendritic impulse-regulating DA autoreceptors (D2) and inhibitory nucleus accumbens-ventral tegmental area (NAc-VTA) feedback processes are involved in the effects (Einhorn et al., 1988). With longer time course (after injection $24 \mathrm{~h}$ ), single cocaine injection (i.p.) increases the firing rate and bursting activity of VTA dopamine neurons, and these increases persist for 7 days (Creed et al., 2016). In addition, during cocaine withdrawal, there is a behavioral depression that is associated with decreased spontaneous activity of VTA dopamine neurons (Koeltzow and White, 2003). Pharmacological effects of cocaine on VTA DA neuronal function have been shown by a single, systemic administration of cocaine to a mouse or a rat, which affects excitatory synaptic transmission onto DA neurons for days (Saal et al., 2003). Cocaine also modulates meso-limbofrontal neurons through an intrinsic mechanism including that cocaine repeated exposure increases voltage-sensitive calcium currents in response to membrane depolarization in medial prefrontal cortex pyramidal neurons (Nasif et al., 2005), repeated cocaine treatment decreases whole-cell calcium current in rat NAc neurons (Zhang et al., 2002), and cocaine withdrawal reduces sodium currents in NAc neurons (Zhang et al., 1998). Collectively, cocaine exhibits very complex effects on meso-limbofrontal system through modulations of DA neuronal function and DA release, which may underlie cocaine-induced behavioral changes.

VTA neurons express a variety of nicotinic acetylcholine receptor (nAChR) subtypes including $\alpha 4 \beta 2, \alpha 7$, and $\alpha 6^{*}$-nAChRs, and activation/desensitization of these nAChRs alters VTA DA neuronal activity and DA release (Klink et al., 2001; Azam et al., 2002; Drenan et al., 2008; Yang et al., 2009a, 2011; Wang et al., 2014). In laboratory animals, stimulation of nAChRs by nicotine (NIC) increases cocaine-induced locomotor sensitization (Schoffelmeer et al., 2002) and also produces long-term increases in both locomotor activity and cocaine self-administration in adolescent but not adult rats (Reed and Izenwasser, 2017). While a nonselective $\mathrm{nAChR}$ antagonist such as mecamylamine reduced cocaine's reinforcement in rats (Blokhina et al., 2005), local injection of a selective $\beta 2^{*}$-nAChR antagonist (dihydro-betaerythroidine, DH $\beta E$ ) into the VTA prevents cocaine-induced locomotor activity (Champtiaux et al., 2006). Pretreatment with nicotine reduces cocaine-conditioned place preference (CPP) established in rats, but inhibition of nAChRs with mecamylamine also slightly attenuates cocaine-induced CPP in rats (Zachariou et al., 2001; Sershen et al., 2010; Levine et al., 2011). Recently, it has been reported that $\alpha 4 \beta 2$ nicotinic receptor desensitizing compounds can decrease the self-administration of cocaine and methamphetamine in rats (Levin et al., 2018). In addition to modulating cocaine-related behavior, differential nicotinic antagonists perfused into the NAc or the VTA also regulate cocaine-induced dopamine release in the NAc of mice (Zanetti et al., 2007). In monkey cocaine self-administration model, the combination of marginally reinforcing doses of cocaine and nicotine increased drug self-administration behavior above levels observed with the same dose of either cocaine or nicotine alone (Mello and Newman, 2011). An $\alpha 4 \beta 2$-nAChR partial agonist, varenicline-induced reduction on nicotine+cocaine combinations is dependent on the dose of cocaine (Mello et al., 2014) although varenicline attenuates the reinforcing effects of nicotine alone but not cocaine alone (Gould et al., 2011; Mello et al., 2014). Considering varenicline is an $\alpha 4 \beta 2-\mathrm{nAChR}$ partial agonist and an $\alpha 7$-nAChR full agonist, the above data suggest that partial activation of $\alpha 4 \beta 2$-nAChRs and/or full activation of $\alpha 7-n A C h R s$ may not play a critical role in the modulations of cocaine selfadministration in monkey. Therefore, in this study, we focus on examination of the effects of cocaine on $\alpha 6$-containing nAChRs.

Accumulating lines of evidence demonstrate that cocaine inhibits heterologously expressed $\mathrm{nAChR}$ subtypes in Xenopus oocytes (Damaj et al., 1999; Francis et al., 2000). Cocaine also inhibits a natural nAChR-mediated current in VTA DA neurons and, consequently, increases the ratio of phasic to tonic DA release, thus potentially enhances its reinforcing effects (AcevedoRodriguez et al., 2014). Additionally, blockade of nAChRs may mediate cocaine craving and addictive effects (Williams and Adinoff, 2008; Crunelle et al., 2010). These lines of evidence suggest an important interaction between cocaine and nAChRs necessitating further investigation. Interestingly, cocaine-induced $\mathrm{CPP}$ is entirely absent in nAChR $\alpha 6$ subunit knockout (KO) mice (Sanjakdar et al., 2015). The VTA expresses multiple nAChR subtypes (Yang et al., 2009a; Wu and Lukas, 2011), but the $\mathrm{nAChR} \alpha 6$ subunit is expressed at the highest concentrations in neurons of the midbrain dopaminergic system, including the VTA and substantia nigra pars compacta (SNc) (Xiao et al., 2009; Yang et al., 2009b, 2011), thus midbrain $\alpha 6^{*}$-nAChRs may play a role in cocaine reward and dependence (Azam et al., 2002; Yang et al., 2009b; Acevedo-Rodriguez et al., 2014). However, 
it is still unknown whether cocaine modulates $\alpha 6^{*}$-nAChRs directly, which is the question this study is designed to address.

In the present study, we evaluated the acute effects of cocaine on $\alpha 6^{*}$-nAChRs heterologously expressed in human epithelial cells using patch-clamp whole-cell recording and found that cocaine noncompetitively inhibits $\alpha 6^{\star}$-nAChR-mediated transmembrane current. Additionally, in mechanically dissociated VTA GABA neurons, $1 \mu \mathrm{M}$ nicotine enhanced spontaneous inhibitory postsynaptic current (sIPSC) frequency, which was sensitive to an $\alpha 6^{*}$-nAChR-selective antagonist ( $\alpha$-conotoxin MII, $\alpha$-Ctx MII, $10 \mathrm{nM})$. This suggests that the nicotine-activated natural $\alpha 6^{*}$-nAChRs are located on GABAergic presynaptic boutons of VTA GABA neurons as we recently described (Steffensen et al., 2018). Interestingly, cocaine $(10 \mu \mathrm{M})$ prevented this nicotine-induced enhancement of sIPSCs, suggesting that cocaine also inhibits natural $\alpha 6^{\star}$-nAChRs. Collectively, our study provides the first evidence that cocaine directly inhibits both heterologously expressed and natural $\alpha 6^{\star}$-nAChRs, suggesting that $\alpha 6^{*}-\mathrm{nAChR}$ is likely a cocaine target which may be involved in the process of cocaine reward and dependence.

\section{MATERIALS AND METHODS}

This study was carried out in accordance with the recommendations of the National Research Council's Guide for the Care and Use of Laboratory Animals. The protocol was approved by the Barrow Neurological Institute's Institutional Animal Care and Use Committee guidelines.

\section{Expression of Human Neuronal $\alpha 6$ /

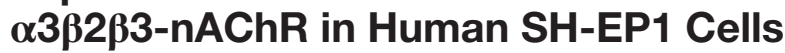

Construction of the human epithelial cell line expressing $\alpha 6 /$ $\alpha 3$ chimera $\alpha 2 \alpha 3-\mathrm{nAChR}(\alpha 6 \mathrm{~N} / \alpha 3 \mathrm{C} \alpha 2 \alpha 3-\mathrm{nAChR})$ was developed by Dr. Whiteaker's laboratory (Breining et al., 2012). The $\alpha 6 /$ $\alpha 3$ denotes a chimeric subunit composed of the extracellular, ligand-binding domain of the human $\alpha 6$ subunit fused to the first transmembrane domain and following the sequence of the human $\alpha 3-n A C h R$ subunit. This approach reproducibly increases expression compared to levels observed with native $\alpha 6$ subunits while retaining $\alpha 6$-like pharmacology (Kuryatov et al., 2000). Consensus-sequence $\alpha 2$ and $\alpha 3$ human nAChR subunit clones were also used. To summarize the salient details, wild-type SH-EP1 cells were transfected with nAChR subunit clones using the cationic polymer Effectene (Qiagen, Valencia, CA). The detailed description of expression procedures and functional and pharmacological properties can be found in our current publication (Chen et al., 2018).

\section{Preparation of Mechanically Dissociated VTA Neurons}

Neurons with functional terminals were obtained by mechanical dissociation as described previously (Akaike and Moorhouse, 2003; Yang et al., 2011; Steffensen et al., 2018). In brief, one midbrain slice was transferred to a $35-\mathrm{mm}$ culture dish (Falcon, Rutherford, NJ) filled with a standard external solution. The region of the slice containing the VTA was directly visualized through an inverted microscope (Nikon, Tokyo, Japan). A firepolished glass pipette with a $50-\mu \mathrm{m}$ diameter tip was mounted to a custom-constructed mechanoelectrical device for cellular dissociation. Using a manipulator, the pipette was then positioned just below the liquid-tissue interface of the VTA region. Neurons close to the surface of the slice were dissociated by horizontal vibration at a frequency of $15-20 \mathrm{~Hz}$ with a range from 0.1 to $0.3 \mathrm{~mm}$ for $2 \mathrm{~min}$. The slice was then removed from the solution containing the dissociated cells. Within $20 \mathrm{~min}$, the isolated neurons adhered to the bottom of the dish and were ready for electrophysiological recordings. These mechanically dissociated neurons differ from neurons dissociated using enzymatic techniques, with the latter losing most, if not all, presynaptic terminals during the dissociation process, the former can, in contrast, retain functional nerve terminals following this process.

\section{Patch-Clamp Whole-Cell Current Recordings From Transfected a6-nAChRs in SH-EP1 Cells}

Standard whole-cell current recordings using a perfusion system allowing fast application and removal of drugs were performed as previously described (Wu et al., 2004, 2006; Yu et al., 2009). Briefly, transfected SH-EP1 cells were prepared in $35-\mathrm{mm}$ culture dishes and then plated on the bottom of the dishes and later placed on the stage of an inverted microscope (IX70 Narishige, Japan). Glass microelectrodes with 3-5 M $\Omega$ resistance between the pipette and extracellular solution were used to form tight seals $(>1 G \Omega)$ on the surface of the cells. The standard whole-cell current recording protocol was initiated by applying a gentle suction to the pipette and continued for 5-10 min to allow for the exchange of the pipette solution and the cytosol to stabilize. Subsequently, recorded cells were gently lifted from the bottom of the culture dishes, which allowed for improved solution exchange and a more accurate evaluation of differences in the kinetics of agonist-induced whole-cell currents. Prior to capacitance and resistance compensation, access resistance (Ra) was measured and deemed acceptable for continuation if observed to be lower than $20 \mathrm{M} \Omega$. Pipette and whole-current capacitance were both minimized, and series resistance was routinely compensated to $80 \%$. Recorded cells were voltageclamped at a holding potential of $-40 \mathrm{mV}$, and inward currents induced by nicotine were measured (Axopatch 200B amplifier; Molecular Devices, Sunnyvale, CA). Current signals were typically filtered at $2 \mathrm{kHz}$, acquired at $5 \mathrm{kHz}$, and displayed and digitized online (Digidata 1440A series A/D board; Molecular Devices, Sunnyvale, CA). Data acquisition and analyses were performed using pClamp10.0 (Molecular Devices), and results were plotted using Origin 8.0 (Origin Lab Corp., North Hampton, MA). All experiments were performed at room temperature $\left(22 \pm 1^{\circ} \mathrm{C}\right)$.

\section{Perforated Patch-Clamp Whole-Cell Recordings Using Dissociated VTA Neurons}

Both perforated and conventional patch-clamp whole-cell recordings were employed (Yang et al., 2011; Steffensen et al., 2018). 
The perforated patch recordings were crucial for obtaining stable nicotinic responses from dissociated midbrain neurons, although the precise mechanism involved is still unclear. The pipettes (3-5 M $\Omega$ ) used for perforated patch recording were filled with intracellular recording solution containing amphotericin B $(200 \mu \mathrm{g} / \mathrm{ml})$. Following tight-seal (2 G $\Omega$ ) formation, conversion to perforated patch mode typically occurred over 5-15 min, which was monitored by changes in access resistance. An access resistance of less than $60 \mathrm{M} \Omega$ was the threshold required to initialize the experimental protocol. Series resistance was not compensated in this study. The data were filtered at $2 \mathrm{kHz}$, acquired at $5 \mathrm{kHz}$, and digitized online (Axon Instruments Digidata 1550 series A/D board, Axon Instruments Inc., Union City, CA). All experiments were performed at room temperature $\left(22 \pm 1^{\circ} \mathrm{C}\right)$. Studies of acutely dissociated neurons were done using cells attached to the cell culture dish, whereas studies of transfected cells expressing human $\alpha 6-n A C h R s$ were lifted from the dish via the recording pipette before initiation of the recording procedure.

\section{Solutions and Drug Application For Transfected $\alpha 6-n A C h R$ SH-EP1 Cells}

The standard external solution for SH-EP1 cells contained (in $\mathrm{mM}$ ): $120 \mathrm{NaCl}, 5 \mathrm{KCl}, 2 \mathrm{MgCl}_{2}, 2 \mathrm{CaCl}_{2}, 25 \mathrm{D}$-glucose, and 10 HEPES; pH 7.4 (Tris-base). For traditional whole-cell recording, the pipette solution contained (in $\mathrm{mM}$ ): 110 Trisphosphate dibasic, 28 Tris-base, 11 EGTA, $2 \mathrm{MgCl}_{2}, 0.5 \mathrm{CaCl}_{2}$, and $4 \mathrm{Na}$-ATP; pH 7.3. In most experiments, nicotine was used as the test agonist and induced whole-cell current responses. Nicotine was quickly perfused onto recorded cells using a computer-controlled U-tube system and the cells were surrounded by applied drugs within $30 \mathrm{~ms}$. The interval between drug applications was optimized to 2 min specifically to ensure the stability of $\mathrm{nAChR}$ responsiveness (i.e. no functional rundown).

\section{For Dissociated VTA Neurons}

The standard external solution contained: (in $\mathrm{mM}$ ) $140 \mathrm{NaCl}$, $5 \mathrm{KCl}, 2 \mathrm{CaCl}_{2}, 1 \mathrm{MgCl}_{2}, 10 \mathrm{HEPES}$, and 10 glucose, $\mathrm{pH}$ adjusted to 7.3 with Tris-base. The amphotericin B-perforated patch-pipette solution used for current-clamp and voltage-clamp recordings contained (in $\mathrm{mM}$ ): $150 \mathrm{~K}$ gluconate, $5 \mathrm{MgCl}_{2}$, and 10 HEPES, pH adjusted to 7.2 with Tris-OH. Amphotericin $\mathrm{B}$ was dissolved in DMSO, and the stock solution was diluted with the internal (patch-pipette) solution to a final concentration of $200 \mu \mathrm{g} / \mathrm{ml}$ just before use. The pipette solution for conventional whole-cell recordings contained (in $\mathrm{mM}$ ): $140 \mathrm{KCl}, 4 \mathrm{MgCl} 2$, 0.1 EGTA, 4 ATP, and 10 HEPES, pH adjusted to 7.4 with $\mathrm{KOH}$. Nicotinic agonists were rapidly delivered into the bath medium by a computer-controlled U-tube system, in which the applied drug surrounds the recorded cell in less than $30 \mathrm{~ms}$. The times between drug applications were adjusted specifically to ensure the stability of $\mathrm{nAChR}$ responsiveness (absence of functional rundown). The drugs used in the present study were ( - ) nicotine and cocaine, which were purchased from Sigma-Aldrich, and $\alpha$-conotoxin MII, which was a gift from Professor Michael McIntosh.

\section{Expression of Human Neuronal $\alpha 6 \mathrm{~N} /$ $\alpha 3 \mathrm{C} \beta 2 \beta 3$ and $\alpha 6 \mathrm{M} 211 \mathrm{~L} / \alpha 3 \mathrm{IC}$ nAChRs in Xenopus Oocytes and Two-Electrode Voltage-Clamp Recording \\ Molecular Constructs}

The human $\alpha 6 \mathrm{~N} / \alpha 3 \mathrm{C}$ chimera was the same as that used for the SH-EP1 transfection, but in an oocyte expression vector, pGEMHE. Human $\alpha 6_{\mathrm{M} 211 \mathrm{~L}} / \alpha 3_{\mathrm{IC}}$ chimera was constructed according to the sequence $\left(\alpha 6_{211 L} / \alpha 3_{\text {cyt }}\right)$ reported by Ley et al. (Ley et al., 2014) from Lindstrom's lab using the Fast cloning and Quikchange methods ( $\mathrm{Li}$ et al., 2012). Human $\beta 2$ and $\beta 3$ wild-type sequences are found in the oocyte expression vector, pSGEM. The cRNAs encoding these subunits were transcribed by T7 RNA polymerase (New England Biolab, Ipswich, MA, USA) using the standard in vitro transcription protocols.

\section{Oocyte Preparation and Injection}

Oocytes were harvested from female Xenopus laevis (Xenopus I, Ann Arbor, MI, USA) as previously described (Xu et al., 2016) by the IACUC-approved protocol of Xenopus Care and Use. The stage VI oocytes were selected and incubated at $16^{\circ} \mathrm{C}$ before injection. Micropipettes for injection were pulled from borosilicate glass (Drummond Scientific, Broomall, PA, USA) on a Sutter P97 horizontal puller, and the tips were cut with forceps to $\approx 40 \mu \mathrm{m}$ in diameter. The cRNA mixture with 1:1:1 ratio $(\alpha 6 / \alpha 3: \alpha 2: \alpha 3)$ was drawn up into the micropipette and injected into oocytes with a Nanoject microinjection system (Drummond Scientific) at a total volume of $\sim 60 \mathrm{nl}$.

\section{Two-Electrode Voltage Clamp}

Three to five days after injection, an oocyte expressing $\alpha 6^{*}$-nAChRs was placed in a home-made small volume chamber and continuously perfused with oocyte Ringer's solution (OR2), which consisted of (in $\mathrm{mM}$ ) $92.5 \mathrm{NaCl}, 2.5 \mathrm{KCl}, 1 \mathrm{MgCl}$, $\mathrm{CaCl} 2$, and 5 HEPES; $\mathrm{pH}$ 7.5. The chamber was grounded through an agar salt bridge to avoid drug influence on junction potential between grounding silver wire and solution. The oocytes were voltage-clamped at $-70 \mathrm{mV}$ to measure acetylcholineinduced currents using a GeneClamp 500B (Axon Instruments, Foster City, CA, USA). The current signal was low-pass filtered at $50 \mathrm{~Hz}$ with the built-in 4-pole low-pass Bessel filter in the GeneClamp 500B and digitized at $100 \mathrm{~Hz}$ with a Digidata1440a and pClamp 10 software (Axon Instruments).

\section{Homology Modeling and Ligand Docking}

Homology modeling of the human $\alpha 6_{\mathrm{M} 211 \mathrm{~L}} \alpha 3_{\mathrm{IC}} \beta 2 \beta 3$ receptor construct was performed using ICM Pro 1.7. The crystal structure of human $\alpha 4 \beta 2$ (with pdbID of 5kxi) was used as the structural template for this receptor. The $\alpha 6_{\mathrm{M} 211 \mathrm{~L}} \alpha 3_{\mathrm{IC}}$ sequence was aligned with the $\alpha 4$ sequence, and $\beta 3$ sequence was aligned with the $\beta 2$ sequence using Clustal Omega. The excess unaligned sequences from N-terminus, C-terminus, and intracellular loop were removed. For the $\alpha 6_{\mathrm{M} 211 \mathrm{~L}} \alpha 3_{\mathrm{IC}}$ subunit used in the model, the majority of $\alpha 3$ intracellular loops were removed (with 17 residues remaining). This chimeric $\alpha$ subunit was modeled using chain $A$ and chain $\mathrm{D}$ as structural templates, whereas $\beta 3$ was modeled 
with chain $\mathrm{C}$ as the template. The pentameric model of $\alpha 6_{\mathrm{M} 211 \mathrm{~L}} \alpha 3_{\mathrm{IC}} \beta 2 \beta 3$ was created by putting these three chain models and original $\beta 2$ crystal structures (chains $B$ and E) together. The new model was further optimized and converted to an ICM object using MolMechanics. The molecular structure of cocaine was obtained from the publicly available crystallographic data corresponding to pdbID of 1q72. Potential ligand-binding domains were identified in the model of whole receptor pentameric structure using "Identify Binding Sites." In addition to the identification of the orthosteric binding sites located along the subunit interfaces, five potential binding sites in the coupling region between amino-terminal domains and transmembrane domains in all five subunit interfaces were identified. The noncompetitive nature of the cocaine-mediated inhibitory effect observed here suggests that its binding site is different from the traditional orthosteric binding region. Since the inhibitory effect is $\alpha 6$ specific, we selected one potential binding site in the coupling region and the interface between chain $\mathrm{D}(\alpha 6)$ and chain $\mathrm{E}(\beta 2)$ for cocaine docking. This is also consistent with the observation that antagonism is not use-dependent as well as that the binding site is not located in the channel domain. The docking conformation with the lowest energy was used for presentation in the Discovery Studio Visualizer 4.0.

\section{Data Analysis and Statistics}

Both peak and steady-state components of inward currents were measured. For dissociated VTA neurons, sIPSCs were analyzed with Clampfit 10.6 software (MDS Analytical
Technologies) as described previously (Gao et al., 2010; Yang et al., 2011). In brief, the sIPSCs were screened automatically using a template with an amplitude threshold of $5 \mathrm{pA}$. These were visually accepted or rejected based on the rise and decay times. More than $95 \%$ of the sIPSCs that were visually accepted were screened using a suitable template, and values of $p<0.05$ were considered significant. Data are presented as means \pm standard errors. Statistical analysis was performed using paired $t$-tests when evaluating data obtained from a single cell and values of $p<0.05$ were considered significant. One-way ANOVA was used. Curve fitting for agonist and antagonist concentrationresponse data was performed (Origin 8.0 software; Origin Lab Corp.) using the logistic equation to provide fits for maximal and minimal responses, $\mathrm{EC}_{50}$ or $\mathrm{IC}_{50}$ values, and Hill coefficients.

\section{RESULTS}

\section{Cocaine Reduces $\alpha 6^{*}$-nAChR-Mediated Whole-Cell Currents in SH-EP1 Cells}

To determine if cocaine affected $\alpha 6^{*}$-nAChR function in SH-EP1 cells, we applied patch-clamp lifted whole-cell recording (Yu et al., 2009) combined with U-tube fast drug application. At a holding potential of $-40 \mathrm{mV}$ (close to the resting membrane potential of SH-EP1 cells), bath application of $1 \mu \mathrm{M}$ nicotine (close to nicotine $\mathrm{EC}_{50}$ concentration) induced an inward current (Figure 1Aa). Co-application of $1 \mu \mathrm{M}$ nicotine and $10 \mu \mathrm{M}$ cocaine reduced $\alpha 6^{\star}$-nAChR-mediated current (Figure 1Ab).

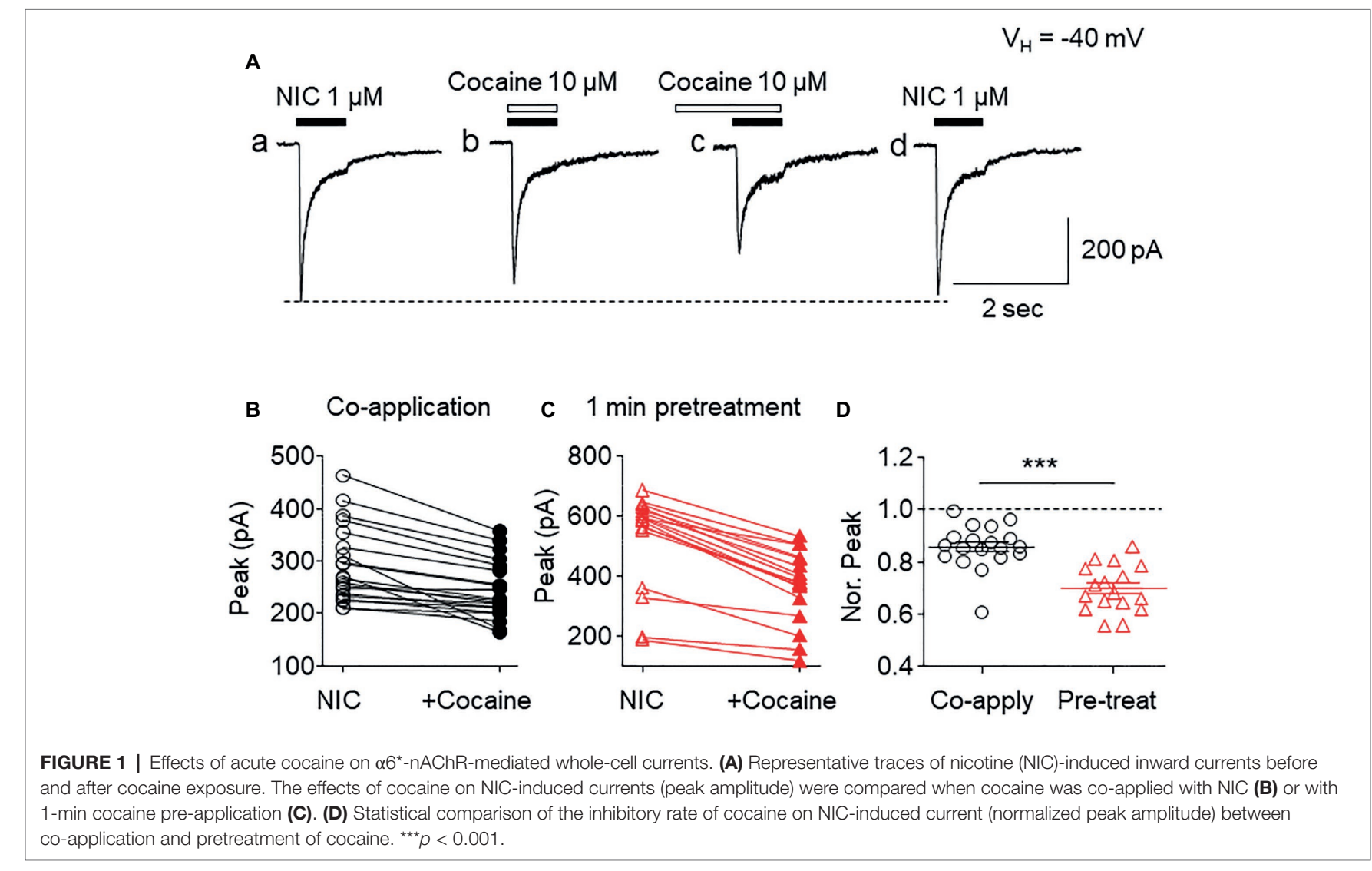


Following pretreatment (1 $\mathrm{min})$, cocaine showed a greater inhibitory effect on inward current compared to $10 \mu \mathrm{M}$ cocaine co-application with nicotine (Figure 1Ac), and following washout of cocaine for $2 \mathrm{~min}$, the inhibitory effect by cocaine was completely recovered (Figure 1Ad). These effects of cocaine are well represented in the pooled data (Figures 1B,C). Statistical analysis showed that the peak amplitude of $1 \mu \mathrm{M}$ nicotineinduced currents was reduced to $84.2 \pm 2.4 \%(n=20, p<0.01$, paired samples $t$-test) by cocaine and nicotine co-application and to $69.7 \pm 2.2 \%(n=17, p<0.001$, paired samples $t$-test $)$ by $1 \mathrm{~min}$ cocaine pretreatment, respectively. The difference between pretreatment and without pretreatment was statistically significant (unpaired $t$-test analysis shows co-application vs. pretreatment, $p<0.001$, Figure 1D). These results suggest that acute cocaine reversibly inhibits $\alpha 6^{\star}$-nAChR-mediated currents. Since pretreatment of cocaine shows greater inhibition than co-application of cocaine with nicotine, all following experiments were performed with 1 min cocaine pretreatment.

\section{Cocaine Inhibits $\alpha 6-n A C h R-M e d i a t e d$ Currents in a Concentration-Dependent Manner}

Pretreatment $(1 \mathrm{~min})$ with cocaine at different concentrations (1-100 $\mu \mathrm{M})$ during 1-second nicotine $(1 \mu \mathrm{M})$ exposure showed a concentration-dependent inhibition in the peak current amplitudes (Figure 2A). The fitting results of concentrationinhibition curves (Figure 2B) showed an $\mathrm{IC}_{50}$ value for cocainemediated inhibition of whole-cell peak current amplitude of $30.1 \mu \mathrm{M}$ and Hill coefficient $=0.9$.

\section{Kinetic Analysis of Cocaine-Induced Inhibition in $\alpha 6^{*}$-nAChR-Mediated Currents}

We examined kinetic changes of $\alpha 6^{*}$-nAChR-mediated wholecell current after acute exposure to $30 \mu \mathrm{M}$ cocaine. As shown in Figure 3, cocaine reduced $1 \mu \mathrm{M}$ nicotine-induced whole-cell current amplitude (Figure 3A), slowed current rising slope

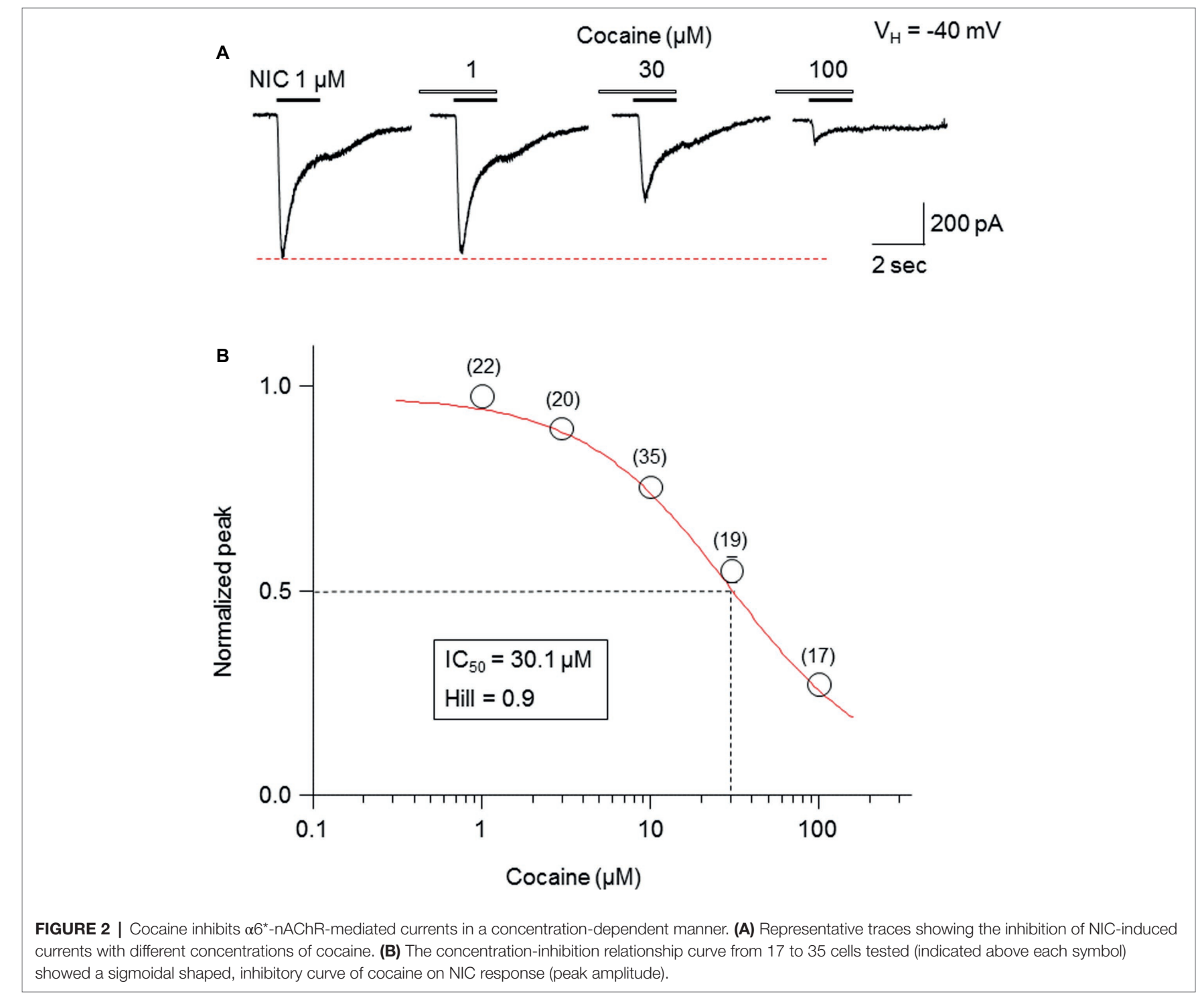



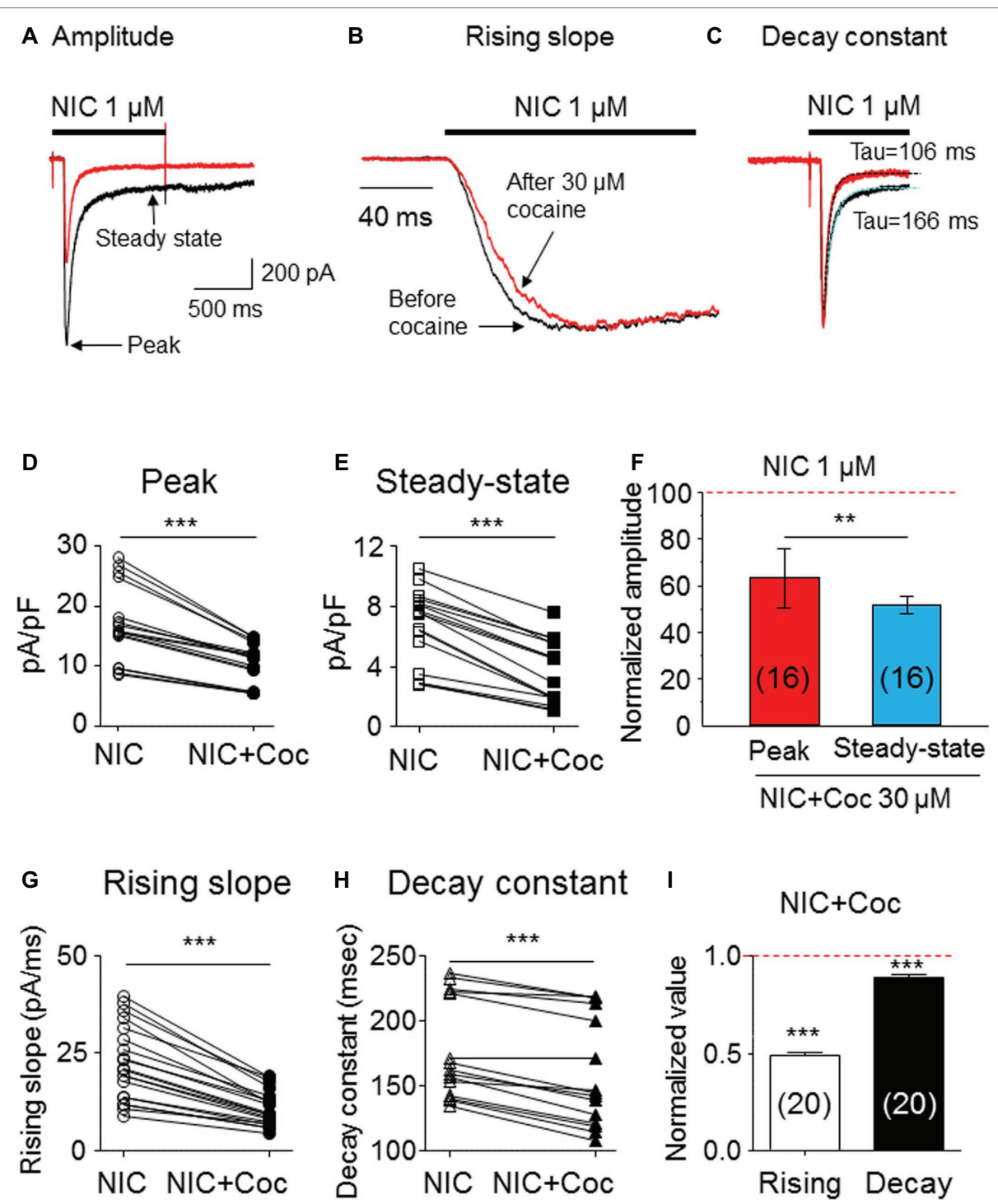

FIGURE 3 | Kinetic analysis of cocaine's effect on $\alpha 6^{\star}-n A C h R$-mediated currents. (A) Superimposed whole-cell current traces before (black) and after (red) cocaine exposure showing a reduced peak and steady-state components. (B) Normalized peak current and expanded time scale to show the rising slope before (black) and after (red) cocaine exposure. (C) Single exponential fitting showed the whole-cell current decay time constant during nicotine exposure before (black) and after (red) cocaine exposure. Statistical comparison of the peak (D) and steady-state (E) components before and after cocaine exposure showed that a cocaine-induced reduction of either peak or steady-state components was highly significant, and the inhibitory effect on steady state was greater (F). (G) Cocaine significantly reduced whole-cell current rising slope. (H) Cocaine significantly accelerated whole-cell current decay constant. (I) The representative inhibitory ratio of cocaine on a whole-cell current rising slope and decay constant. The horizontal dashed lines in F and I indicate the level of nicotine-induced whole-cell current before cocaine exposure, which was normalized to $1.0 .{ }^{* *} p<0.01$ and ${ }^{* \star *} p<0.001$.

(Figure 3B), and accelerated decay rate (Figure 3C). Statistical analysis demonstrated that after $30 \mu \mathrm{M}$ cocaine exposure (with 1-min pretreatment), whole-cell current density of the peak component was reduced from $17.1 \pm 1.6$ to $10.5 \pm 0.9 \mathrm{pA} /$ $\mathrm{pF}$ [paired $t$-test, $p<0.001, n=16$ (Figure 3D)], and the steady-state component was reduced from $6.7 \pm 0.6$ to $3.7 \pm 0.5 \mathrm{pA} / \mathrm{pF}$ [paired $t$-test $p<0.001, n=16$ (Figure 3E)]. Comparison of the inhibitory ratio by cocaine on peak $(62.6 \pm 1.8 \%)$ and steady-state $(51.8 \pm 3.7 \%)$ components showed a highly significant difference [unpaired $t$-test, $p<0.001$ (Figure 3F)]. In 20 cells tested, $30 \mu \mathrm{M}$ cocaine slowed $\alpha 6^{*}-\mathrm{nAChR}$ channel activation represented as a reduced current rising slope [from $-22.5 \pm 2.1$ to $-10.9 \pm 1.0 \mathrm{pA} / \mathrm{ms}$, paired $t$-test $p<0.001$, $n=20$ (Figure 3G)] and accelerated $\alpha 6^{*}-n A C h R$ channel inactivation measure by current decay constant [Tau numbers from $212.4 \pm 15.8$ to $194.2 \pm 15.7 \mathrm{~ms}$, paired $t$-test $p<0.01$, $n=20$ (Figure $3 \mathrm{H})$ ]. Therefore, the inhibitory ratio by $30 \mu \mathrm{M}$ cocaine for channel activation was $50.8 \pm 1.5 \%$ [paired $t$-test $p<0.001$ (Figure 3I)] and for the channel, inactivation was $9.5 \pm 1.6 \%$ [paired $t$-test $p<0.01$ (Figure 3I)]. These results suggest that acute cocaine inhibits nicotine-induced currents through both channel activation and inactivation phases. 


\section{Cocaine Inhibits $\alpha 6^{*}$-nAChR-Mediated Currents Induced by Different NIC Concentrations}

To determine the mechanism of how cocaine affects nicotineinduced responses, the nicotine concentration-response relationship curves with or without $30 \mu \mathrm{M}$ cocaine (with 1 min pretreatment) were compared. As shown in Figure 4, nicotine-induced inward currents increased with increasing NIC concentrations (Figure 4A), forming a sigmoidal-shaped concentration-relationship curve (Figure 4C, open symbols). In the presence of $30 \mu \mathrm{M}$ cocaine, the different concentrations of nicotine-induced currents were reduced (Figure 4B) compared to nicotine exposure alone (Figure 4C, filled symbols). Paired $t$-test analysis for each nicotine concentration pair with $30 \mu \mathrm{M}$ cocaine showed highly significant differences between nicotine alone and nicotine plus cocaine at all nicotine concentrations between 0.01 and $100 \mu \mathrm{M}$. Using sigmoidal fitting, the $\mathrm{EC}_{50}$ values of NIC-induced whole-cell peak current was $0.42 \mu \mathrm{M}$ and Hill coefficient was 0.8 , while with $30 \mu \mathrm{M}$ cocaine, the $\mathrm{EC}_{50}$ values of nicotine plus cocaine-induced whole-cell peak current was $0.45 \mu \mathrm{M}$ and Hill coefficient was 0.9; the $\mathrm{EC}_{50}$ values of nicotine with and without cocaine were not significantly different (unpaired $t$-test). Collectively, cocaine reduces the maximal NIC response of the NIC concentration-response curve (Figure 4C) but does not change the $\mathrm{NIC} \mathrm{EC}_{50}$ value (Figure 4D), suggesting a noncompetitive inhibitory mechanism.

\section{Cocaine Inhibitory Effect on $\alpha 6-n A C h R-$ Mediated Current Is Not Use-Dependent}

To determine whether the open channel block mechanism underlies the cocaine-induced noncompetitive inhibition in the $\alpha 6^{*}$-nAChR-mediated current, we examined a use-dependent feature of cocaine inhibition. We compared the current decline ratio with four repetitive applications at 15-s interval of nicotine (use-dependent) or only two applications of nicotine given at a 60 -s interval (nonuse-dependent) when cocaine $(30 \mu \mathrm{M})$ was persistently present. As shown in Figure $\mathbf{5 A}$, repetitive applications (four times at 15-s interval) of nicotine $(1 \mu \mathrm{M}$ for $1 \mathrm{~s}$ ) with the continuous presence of $30 \mu \mathrm{M}$ cocaine led to nearly unvarying suppression in the nicotine-induced currents, and following washout for $2 \mathrm{~min}$, the nicotine response completely recovered. Under the same experimental conditions, repetitive applications of nicotine $(1 \mu \mathrm{M}$ for $1 \mathrm{~s})$ twice (with

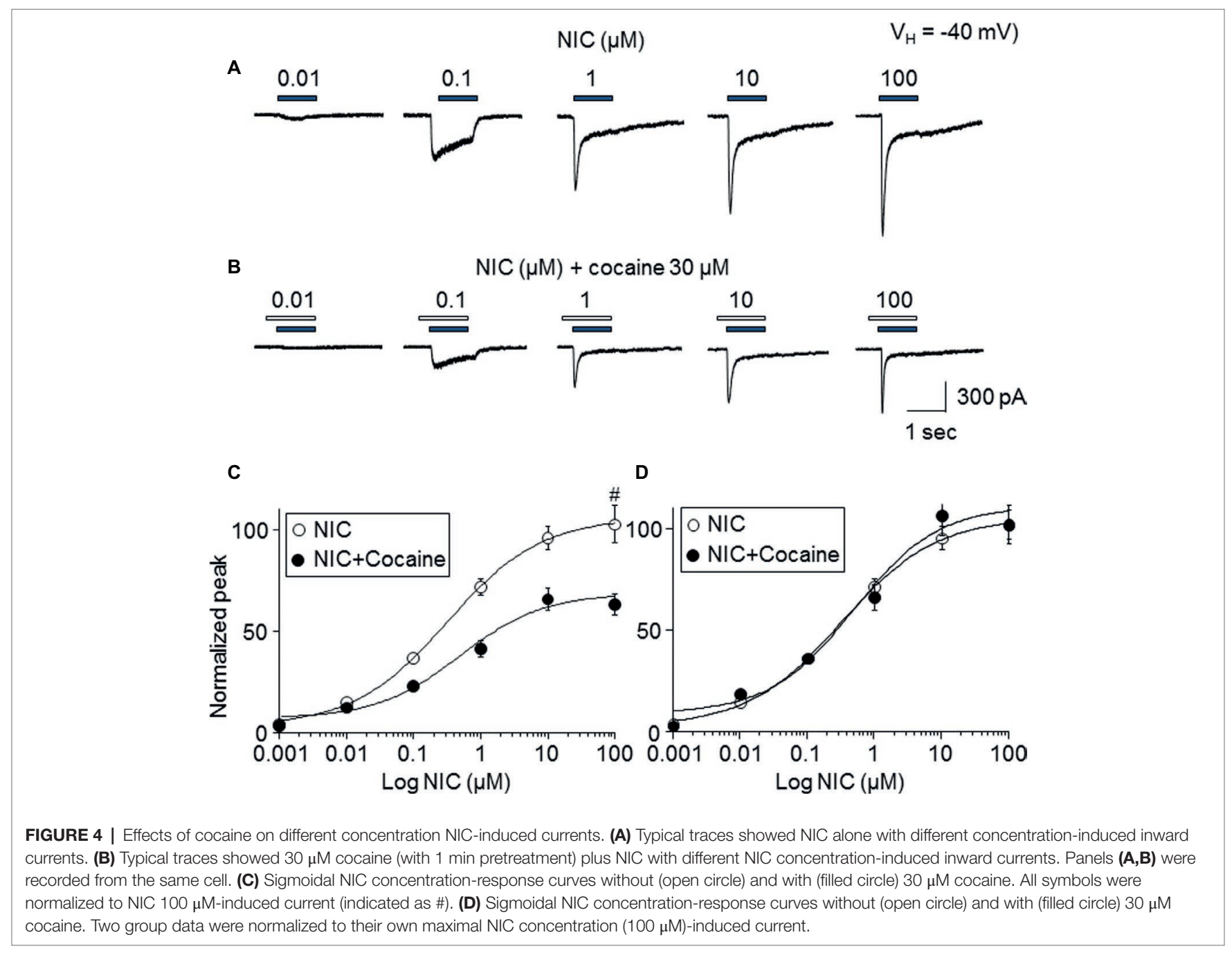


$60 \mathrm{~s}$ interval) in the continuous presence of $30 \mu \mathrm{M}$ cocaine led to a similar suppression in the NIC-induced currents (Figure 5B). Again, following 2-min washout, the nicotine response completely recovered. In six cells tested, the nicotine response declined to the same level using these two experimental protocols when cocaine was persistently present (Figure 5C). Comparison of current declined ratio between the use (4th nicotine response/1st nicotine response) and nonuse (2nd nicotine response/1st nicotine response) protocols showed no significant difference (Figure 5D), suggesting that cocaine inhibition of $\alpha 6^{*}$-nAChR-mediated current is not use-dependent.

\section{Cocaine Inhibition of $\alpha 6-n A C h R-M e d i a t e d$ Current Is Not Mediated Through Intracellular Targets}

To test whether the cocaine-induced inhibition in $\alpha 6^{*}$-nAChRmediated current occurs at an extracellular or intracellular target, we added $30 \mu \mathrm{M}$ cocaine into the recording electrode. Following the formation of the whole-cell recording configuration for 3-5 min to allow cocaine to infuse into the cell, we examined repetitive nicotine-induced current response $(1 \mu \mathrm{M}$ for $1 \mathrm{~s}$, repeated five times at 15 -s interval) under this intracellular cocaine condition. Figure 6 demonstrates that intracellular administration of $30 \mu \mathrm{M}$ cocaine produced five stable and unchanged repetitive nicotine-induced current responses (Figure 6A). While there was no change in the nicotine response in the presence of intracellular cocaine, bath application of $30 \mu \mathrm{M}$ cocaine inhibited the nicotine response (Figure 6B). Figure 6C summarizes the pooled data, in which the nicotine-induced current showed no difference with versus without internal cocaine. Figure 6D summarizes the data showing that the intracellular cocaine did not alter nicotine response, whereas the bath application of cocaine inhibited nicotine response. These results suggest that cocaine inhibits $\alpha 6^{*}$-nAChR-mediated current through extracellular sites.

\section{Effects of Cocaine on $\alpha 6 \mathrm{~N} / \alpha 3 \mathrm{C} / 2 \mathrm{2} \beta 3$ - and $\alpha 6_{\mathrm{M}_{211}} \alpha 3_{\mathrm{IC}} \beta 2 \beta 3-\mathrm{nAChRs}$ Expressed in Xenopus Oocytes}

Data presented thus far demonstrate that acute exposure to cocaine inhibits an $\alpha 6^{*}$-nAChR-mediated current in human SH-EP1 cells. Since simply transfecting WT nAChR $\alpha 6$ with any other $\beta$ subunits into the expression system does not result in functional receptors, we used an $\alpha 6 \mathrm{~N} / \alpha 3 \mathrm{C} \beta 2 \beta 3$ combination and transfected it into SH-EP1 cells. Our previous publications show these transfected cells exhibit excellent function with the features consistent with $\alpha 6^{*}$-nAChR pharmacology and physiology (Damaj et al., 1999; Francis et al., 2000). To explore the possibility

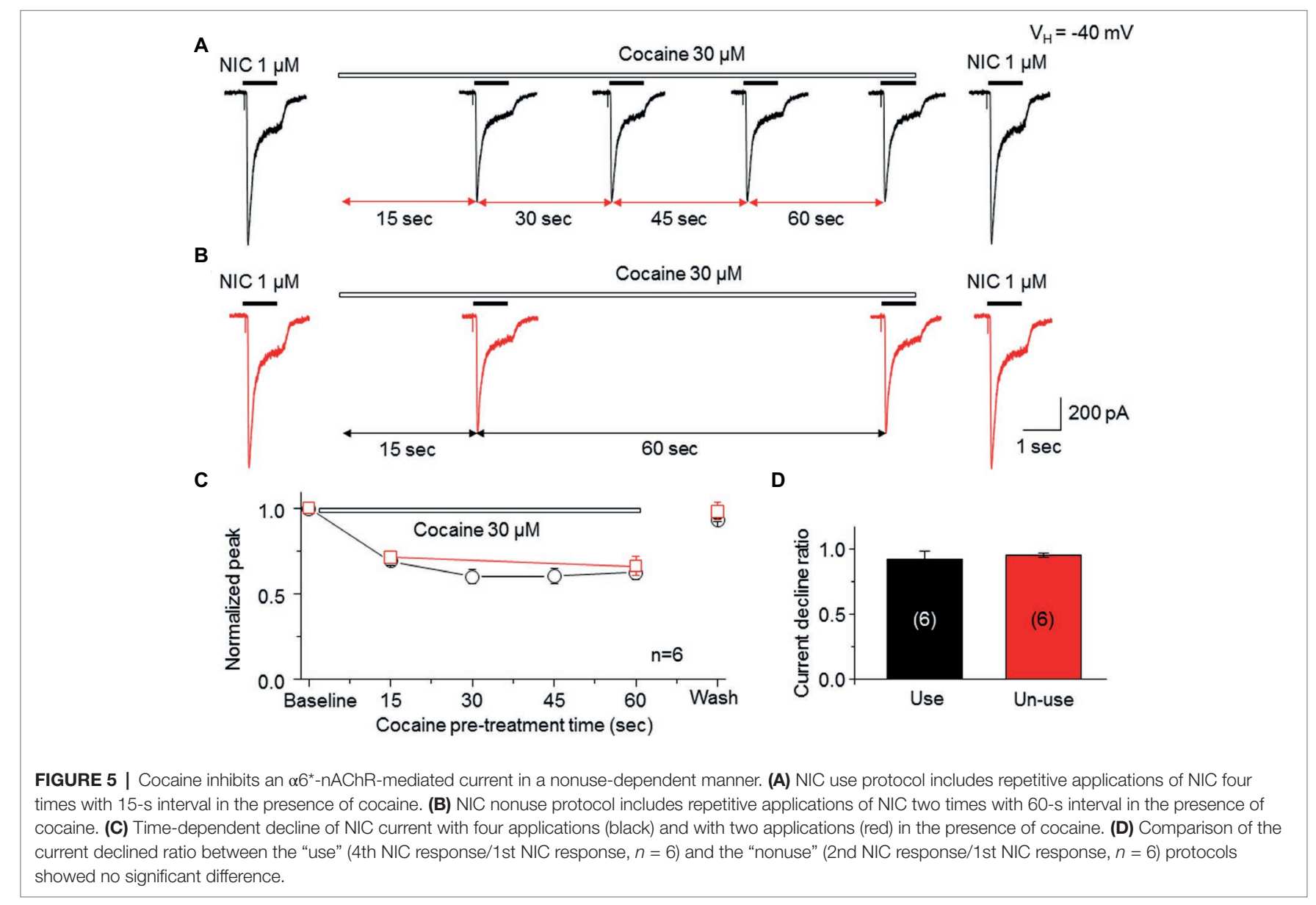




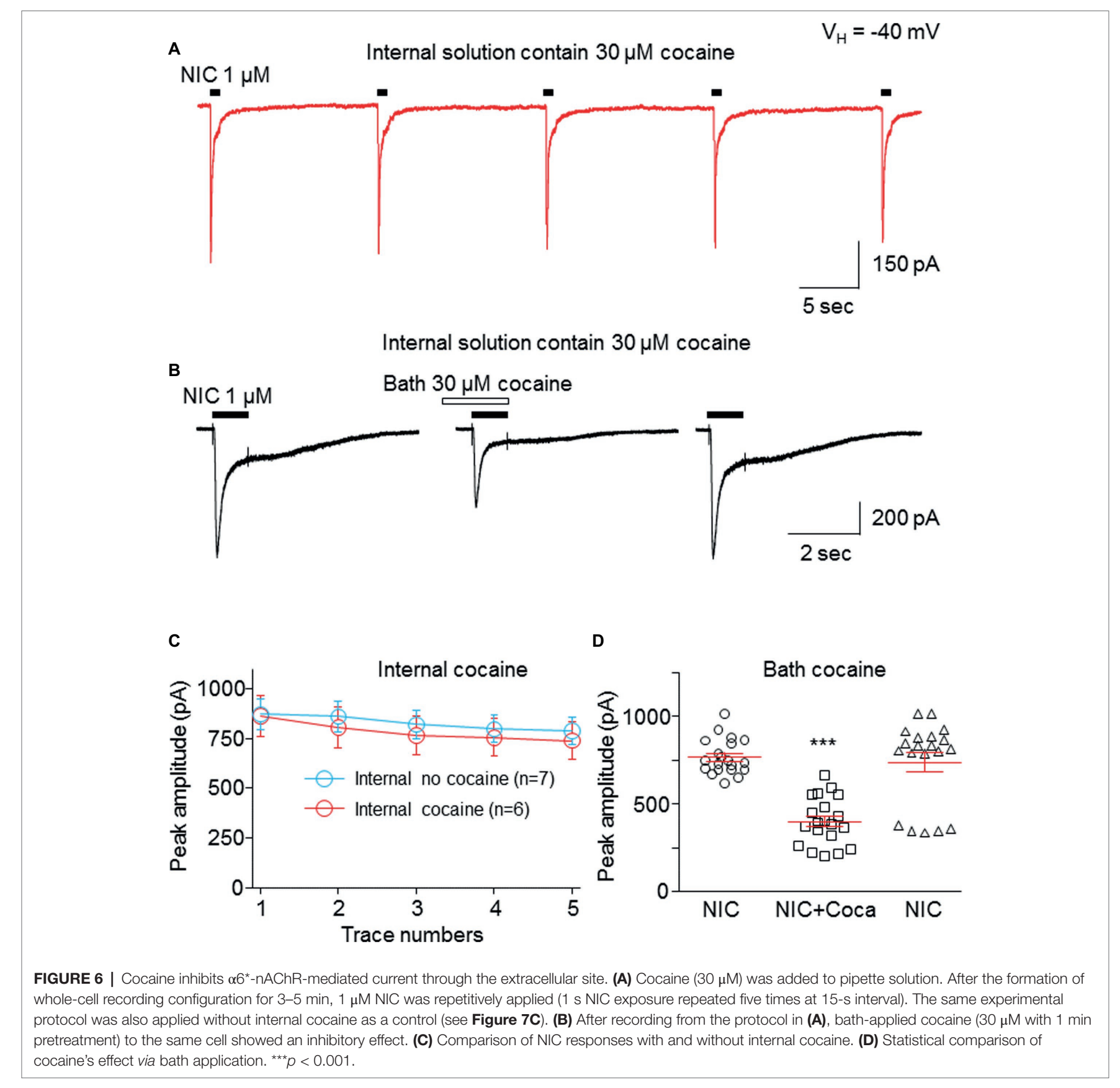

that cocaine acts on the $\alpha 6$ subunit, we followed a recent report (Ley et al., 2014) to create a mutant $\alpha 6_{\mathrm{M} 211 \mathrm{~L}} / \alpha 3_{\mathrm{IC}}$. The receptor $\mathrm{N}$ terminal and four transmembrane domains are formed from $\alpha 6$ with a single point mutation (e.g., M211 L), and only the second intracellular loop is from $\alpha 3$. With this subunit combination, the receptor contains primarily $\alpha 6$ content. We compared cocaine effects on the $\alpha 6 \mathrm{~N} / \alpha 3 \mathrm{C} \beta 2 \beta 3$-nAChR (Figure 7A), and the $\alpha 6_{\mathrm{M} 211 \mathrm{~L}} /$ $\alpha 3_{\text {IC }} \beta 2 \beta 3-n A C h R$ (Figure 7C) expressed in Xenopus oocytes using the two-electrode voltage-clamp recording. The results demonstrated that cocaine $(30 \mu \mathrm{M}$ with $1 \mathrm{~min}$ pretreatment) inhibited $500 \mathrm{nM}$ ACh (close to ACh $\mathrm{EC}_{50}$ )-induced currents with a similar inhibitory rate in these two variants of $\alpha 6^{*}$-nAChRs
(Figures $7 \mathbf{B}, \mathbf{D}, \mathbf{E})$. These results suggest that cocaine likely acts on the $\alpha 6$ subunit to inhibit $\alpha 6^{*}$-nAChR-mediated current. To determine the potential binding site of cocaine in the nicotinic receptor, we docked cocaine to the homology model of $\alpha 6_{\mathrm{M} 211 \mathrm{~L}} \alpha 3_{\mathrm{IC}} \beta 2 \beta 3 \mathrm{nAChR}$ with ICM Pro 1.7 software (see Methods for detail). The docking conformation with the lowest energy was used for presentation. As shown in Figure 8, cocaine docked to a potential binding pocket in the subunit interface between $\alpha 6_{\mathrm{M} 21 \mathrm{~L}} \alpha 3_{\text {IC }}$ and $\beta 2$ subunits (Figure $8 \mathrm{~A}$ ) and the coupling region between the $\mathrm{N}$-terminal domain and a transmembrane domain (Figure 8B). Figure 8C compares the binding sites between nicotine (top) and cocaine (bottom). 

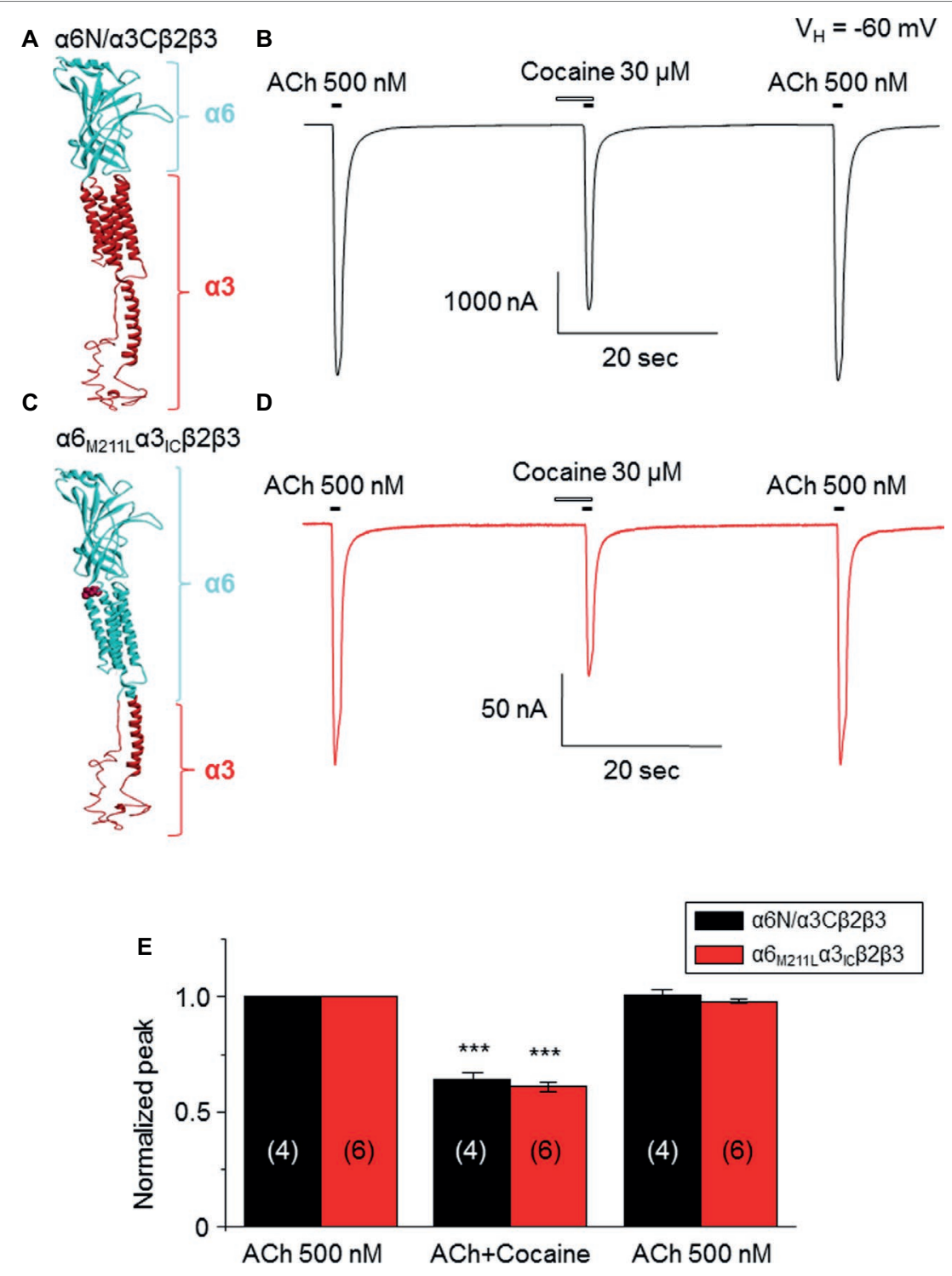

FIGURE 7 | Cocaine inhibits two types of $\alpha 6^{*}$-nAChR-mediated currents in Xenopus oocytes. (A) 3D structure of the $\alpha 6$ N $\alpha 3 C$ subunit, which is similar to the heterologously transfected $\alpha 6 / \alpha 3$ chimera in human EH-EP1 cells. (B) Cocaine inhibited ACh-induced current in the $\alpha 6 \mathrm{~N} / \alpha 3 \mathrm{C} \beta 2 \beta 3-\mathrm{nAChR}$. (C) 3D structure of the $\alpha 6_{\mathrm{M} 211} \alpha 3_{1 C}$ subunit, which contains more content ( $N$-terminal and four transmembrane domains) of $\alpha 6$ subunit. (D) Acute cocaine effect on the $\alpha 6_{M 211} \alpha 3_{1} \beta 2 \beta 3$ nAChR. (E) Statistical comparison of cocaine's effect on $\alpha 6 \mathrm{~N} \alpha 3 \mathrm{C} \beta 2 \beta 3 \mathrm{nAChR}$ - and $\alpha 6_{\mathrm{M} 211 \mathrm{~F}} \alpha 3_{{ }_{1}} \beta 2 \beta 3 \mathrm{nAChR}$-mediated currents, with the similar inhibitory rate. ${ }^{\star * \star} p<0.001$ (paired $t$-test) when cocaine effect is compared to the control.
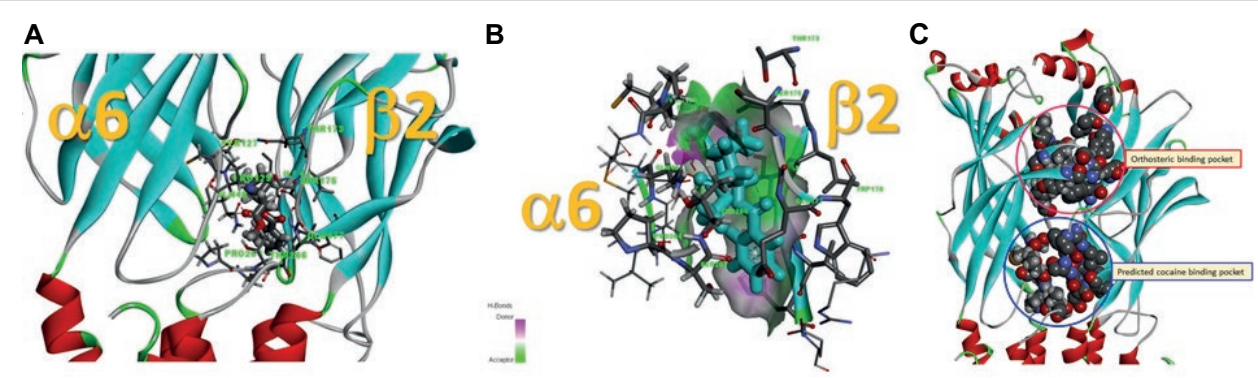

FIGURE 8 | Potential cocaine binding site in the $\alpha 6_{\mathrm{M} 211} \alpha 3_{1} \beta 2 \beta 3-n A C h R$. (A) Cocaine docked to a potential binding pocket identified by the software in the subunit interface between $\alpha 6_{\mathrm{M} 211} \alpha 3_{\mathrm{IC}}$ and $\beta 2$ subunits and in the coupling region between $\mathrm{N}$-terminal domain and a transmembrane domain. (B) $\mathrm{A}$ closer look at the potential cocaine interactions with the receptor. (C) Comparison of the binding sites between nicotine (orthosteric binding pocket) and cocaine (predicted cocaine binding pocket). 


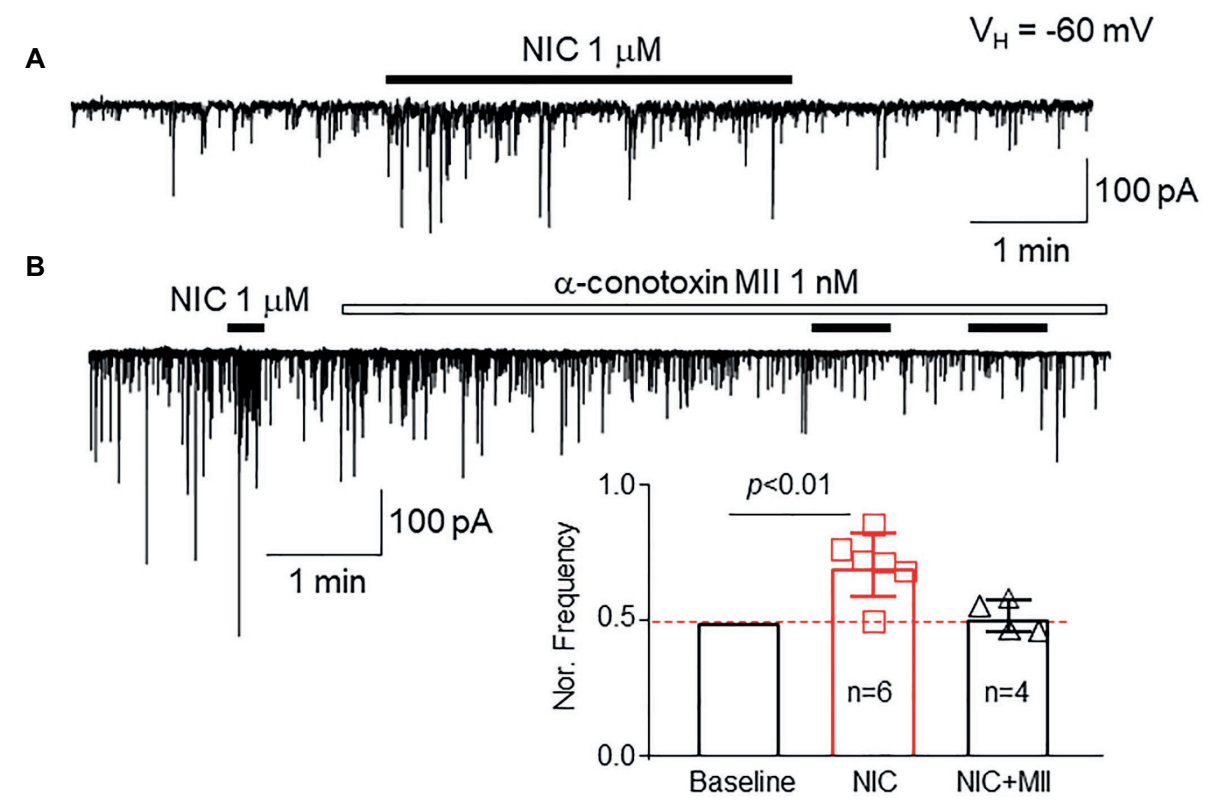

C
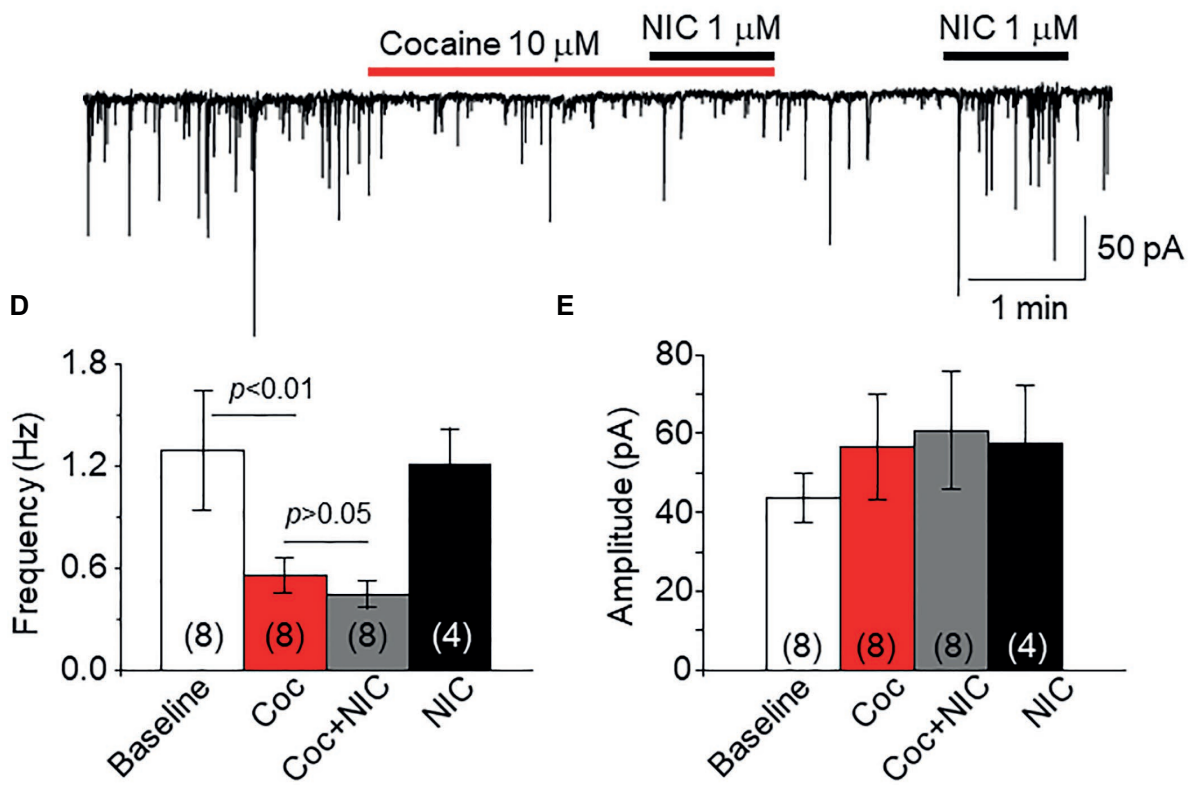

FIGURE 9 | Cocaine inhibits natural $\alpha 6^{\star}$-nAChRs expressed on GABAergic boutons on VTA DA neurons. (A) In mechanically dissociated VTA GABA neurons, patchclamp whole-cell recording in voltage-clamp mode demonstrated sIPSCs and bath application of $1 \mu \mathrm{M}$ NIC enhanced sIPSC frequency. (B) Pretreatment with the $\alpha 6^{\star}-$ nAChR selective antagonist, $\alpha$-conotoxin MII (1 nM for 5 min) prevented NIC-induced effect, suggesting that $\alpha 6^{\star}$-nAChRs mediate the NIC effect. (C) Bath application of cocaine $(10 \mu \mathrm{M})$ reduced the sIPSC frequency, and in the presence of cocaine, NIC faired to enhance sIPSCs. After washout of cocaine for 1 min, NIC enhanced sIPSCs. Statistical analysis of the effects of cocaine on sIPSCs and NIC-induced effect demonstrated that compared to a baseline level, cocaine significantly reduced the sIPSC frequency, and in the presence of cocaine, NIC faired to enhance sIPSC frequency (D). However, cocaine did not affect sIPSC amplitude (E).

\section{Cocaine Inhibits Natural $\alpha 6^{*}$-nAChRs on VTA GABAergic Boutons on DA Neurons}

To examine the effects of cocaine on natural $\alpha 6^{*}$-nAChRs, we used a mechanically dissociated VTA DA neuron model, in which we have demonstrated that functional $\alpha 6^{*}$-nAChRs are expressed on GABAergic presynaptic boutons synapsed onto DA neurons (Yang et al., 2011). As shown in Figure 9A, we recorded sIPSCs in isolated single DA neurons under voltageclamp recording mode, and bath application of $1 \mu \mathrm{M}$ nicotine increases sIPSCs frequency. However, after pretreatment for $5 \mathrm{~min}$ with an $\alpha 6^{*}$-nAChR-selective antagonist, $\alpha$-Ctx MII ( $1 \mathrm{nM})$, the nicotine-induced enhancement of sIPSCs was abolished (Figure 9B), suggesting that the NIC-induced effect is mediated through presynaptic $\alpha 6^{*}$-nAChRs. By using this cell model, bath application of cocaine $(10 \mu \mathrm{M})$ suppressed 
the sIPSC frequency but not amplitude, and under this condition in the presence of cocaine, bath application of NIC failed to enhance sIPSCs (Figure 9C). In four cells tested, bath application of nicotine enhanced sIPSC frequency again following a 5-min washout of cocaine. Statistical analysis showed that cocaine inhibited sIPSC frequency and prevented nicotine-induced enhancement of sIPSCs (Figure 9D), but cocaine did not show significant effects on sIPSC amplitude (Figure 9E). These results suggest that cocaine can inhibit $\alpha 6^{*}$-nAChRs naturally expressed on GABAergic presynaptic boutons synapsing on VTA DA neurons.

\section{DISCUSSION}

This study suggests that cocaine directly inhibits $\alpha 6^{*}$-nAChR function, which is a novel finding. By using heterologously expressed $\alpha 6^{\star}$-nAChRs in human SH-EP1 cells, we demonstrate that bath-applied cocaine inhibits an $\alpha 6^{*}$-nAChRs-mediated wholecell current in a concentration-dependent manner with an $\mathrm{IC}_{50}$ value of $30 \mu \mathrm{M}$. Kinetic analysis shows that cocaine slows nicotine channel activation and accelerates $\alpha 6^{*}$-nAChR desensitization, which together reduces the amplitude of the nicotine-induced current. Cocaine inhibits $\alpha 6^{\star}$-nAChRs through an extracellular site in a noncompetitive way, but not in a use-dependent way. In Xenopus oocytes, cocaine equally inhibits $\alpha 6 \mathrm{~N} \alpha 3 \mathrm{C} \beta 2 \beta 3$ - and $\alpha 6_{\mathrm{M} 21 \mathrm{~L}} \alpha 3_{\mathrm{IC}} \beta 2 \beta 3$-mediated currents, suggesting that the $\alpha 6$ subunit is likely the target for cocaine inhibition, which is further confirmed by docked prediction modeling. In mechanically dissociated VTA DA neurons, cocaine inhibits $\alpha 6^{*}$-nAChRs-mediated enhancement of sIPSC frequency, suggesting that cocaine can inhibit natural presynaptic $\alpha 6^{*}$-nAChR function. Together, this study provides the first evidence that cocaine directly inhibits $\alpha 6^{*}$-nAChR function, suggesting that $\alpha 6^{*}$-nAChRs may play an important role in cocaine reward and dependence.

\section{Heterologously Expressed $\alpha 6^{*}$-nAChR Is a Good Cell Model to Test Cocaine's Effects}

nAChRs containing $\alpha 6$ subunits are not widely expressed in the brain, but are prevalent in midbrain dopamine neurons. Thus, $\alpha 6^{*}$-nAChRs are associated with pleasure, reward, and mood control (Klink et al., 2001; Azam et al., 2002), suggesting that $\alpha 6^{*}$-nAChRs may play critical roles in drug reward and addiction (Shytle et al., 2002). However, the functional and pharmacological properties of $\alpha 6^{*}$-nAChRs are largely unknown because of two major reasons: (1) there are no selective $\alpha 6^{*}-\mathrm{nAChR}$ agonists and (2) examining the function of heterologous expression of $\mathrm{nAChR} \alpha 6$ subunit with other $\beta$ subunits has proven challenging. Previous studies showed that heterologous expression of $\alpha 6$ in any combination involving $\beta 2$ subunits that result in functional ion channels is extremely difficult to study at a functional level. However, chimeric subunits where the $\mathrm{N}$-terminal domain of $\alpha 6$ is fused to the transmembrane domain of $\alpha 3$ or $\alpha 4(\alpha 6 / \alpha 3$ or $\alpha 6 / \alpha 4)$ were found to produce functional receptors with $\beta 2$ or $\beta 4$ subunits (Kuryatov et al., 2000). In the present study, we used an established functional $\alpha 6^{*}-\mathrm{nAChR}$ developed through co-transfection of $\alpha 6 / \alpha 3$ chimera and $\beta 2, \beta 3$ subunits into a human SH-EP1 cell line (Breining et al., 2012). We recently profiled the functional and pharmacological features of this $\alpha 6^{*}$-nAChR and showed that this transfected $\alpha 6^{*}$-nAChR exhibits excellent function and is consistent with $\alpha 6^{*}$-nAChR pharmacology (Chen et al., 2018), yielding an effective cell model to evaluate the effects of cocaine on $\alpha 6^{*}$-nAChR function.

\section{Cocaine Inhibits the $\alpha 6^{\star}$-nAChR Function}

It has been reported that cocaine inhibits heterologously expressed nAChR function in Xenopus oocyte. For example, Damaj et al. reported that cocaine inhibits heterologously expressed nAChR-mediated current in a concentrationdependent manner with the $\mathrm{IC}_{50}$ range of $4.4-6.9 \mu \mathrm{M}$ for $\alpha 4 \beta 2-n A C h R s$ and $22-42.3 \mu \mathrm{M}$ for $\alpha 3 \beta 2-n A C h R s$ (Damaj et al., 1999). They found that cocaine-induced inhibition in nAChR function is through a noncompetitive mechanism (Damaj et al., 1999). Francis et al. systematically compared cocaine-induced inhibition in different subtypes of nAChRs expressed in oocytes and found that $\alpha 4 \beta 4-\mathrm{nAChRs}$ exhibited the highest sensitivity with the $\mathrm{IC}_{50}$ of $2 \mu \mathrm{M}$ and $\alpha 3 \beta 2$ showed the lowest sensitivity with the $\mathrm{IC}_{50}$ of $60 \mu \mathrm{M}$ (Francis et al., 2000). In addition to these expressed nAChRs, AcevedoRodriguez et al. found that cocaine also inhibits native nAChRs ( $\beta 2$-containing) in midbrain dopaminergic neurons with the IC $_{50}$ of $19.8 \mu \mathrm{M}$ (Acevedo-Rodriguez et al., 2014). Collectively, these previous data suggest that cocaine serves as a low-affinity antagonist on different subtypes of $\mathrm{nAChRs}$ with varying affinities. However, thus far, whether cocaine modulates $\alpha 6^{*}-\mathrm{nAChR}$ function is unknown. The present study provides the first evidence that within a physiologically relevant concentration range, cocaine inhibits $\alpha 6^{\star}-\mathrm{nAChR}$ function in a concentration-dependent manner with an $\mathrm{IC}_{50}$ value of $30 \mu \mathrm{M}$. Within the nicotine concentration-response curve, different nicotine concentrations with $30 \mu \mathrm{M}$ cocaine reduce the maximal nicotine concentration-induced current without changing the nicotine $\mathrm{EC}_{50}$ value, suggesting a noncompetitive inhibition. Our data are consistent with previous reports that also expressed nAChRs in Xenopus oocytes and demonstrated that cocaine inhibits human $\alpha 6^{*}$-nAChRs heterologously expressed in human SH-EP1 cells. In addition to using expressed $\alpha 6^{*}$-nAChRs, we also tested the effects of cocaine on natural $\alpha 6^{*}$-nAChRs located on GABAergic presynaptic boutons/ terminals on VTA DA neurons (Yang et al., 2011). Thus far, it is difficult to record $\alpha 6^{*}$-nAChR-mediated whole-cell current in wild-type rodents unless gained $\alpha 6^{*}$-nAChR transgenic mice are used (Engle et al., 2013). Even in the gained $\alpha 6$ subunit transgenic mice, the $\alpha 6$ subunit is likely assembled with an $\alpha 4$ subunit to form the $\alpha 4 \alpha 6$-containing nAChRs (Drenan et al., 2008). Previously, we found functional $\alpha 6^{*}$-nAChRs located on presynaptic GABAergic boutons/terminals on VTA DA neurons (Yang et al., 2011) and also on GABA neurons (Steffensen et al., 2018). In the present study, we tested the effects of cocaine on the function of these presynaptic $\alpha 6^{*}$-nAChRs. As shown in Figure 9, the presynaptic $\alpha 6^{*}$-nAChRs can be activated by $1 \mu \mathrm{M}$ nicotine, which can then be abolished by $1 \mathrm{nM}$ a-Ctx MII. By using this cell model, we showed 
that $10 \mu \mathrm{M}$ cocaine abolished the nicotine $(1 \mu \mathrm{M})$-induced increase in SIPSC frequency. These results suggest that cocaine inhibits presynaptic $\alpha 6^{*}$-nAChR function with a higher potency compared to expressed $\alpha 6^{\star}$-nAChR. Interestingly, AcevedoRodriguez et al. found that cocaine-induced inhibition of presynaptic nAChR-mediated $\mathrm{Ca}^{2+}$ release is more sensitive than that of postsynaptic nAChRs located on the cell body (Acevedo-Rodriguez et al., 2014).

\section{Mechanisms of Cocaine-Induced Inhibition in $\alpha 6^{*}$-nAChRs}

In this study, we designed a series of experiments to explore the possible mechanisms of cocaine-induced inhibition in $\alpha 6^{*}$-nAChR. First, we compared nicotine concentration-response curves with or without $30 \mu \mathrm{M}$ cocaine. We showed that in the presence of cocaine, the nicotine concentration-response curve was shifted downward without changing the $\mathrm{EC}_{50}$ value, suggesting noncompetitive inhibition, which is consistent with the cocaine-induced inhibition in other subtypes of nAChRs (Damaj et al., 1999; Francis et al., 2000). Second, we performed the use-dependent experiment and found that cocaine-induced inhibition was not use-dependent, suggesting that cocaineinduced inhibition in $\alpha 6^{*}$-nAChR may not be mediated through an open channel block mechanism. Third, through the kinetic analysis, we found that cocaine slowed nicotine channel opening kinetics and accelerated $\alpha 6^{*}$-nAChR desensitization during nicotine exposure. Finally, we applied cocaine intracellularly through the recording electrode and found that intracellular cocaine did not affect $\alpha 6^{*}$-nAChR function, suggesting that cocaine acts on an extracellularly located site.

\section{Significances and Limitations}

We have provided evidence that cocaine inhibits heterologously expressed and natural $\alpha 6^{*}$-nAChR function. Since these receptors are localized in brain regions associated with pleasure, reward, drug reinforcement, drug dependence, control of mood and emotion, and control of attention, $\alpha 6^{\star}$-nAChRs could play important roles in the modulation of these functions. Especially, midbrain DA neurons and associated circuits play a major role in drug reward and dependence, and $\alpha 6^{*}$-nAChRs play a critical role in modulation of mesolimbic function. Therefore, the finding that cocaine directly inhibits $\alpha 6^{*}$-nAChRs is highly significant toward understanding cocaine targets, mechanisms, and therapeutics. For instance, we show that cocaine prevents cholinergic ( $1 \mu \mathrm{M}$ nicotine) enhancement of presynaptic sIPSCs on VTA DA neurons, in turn enhancing VTA DA neuron activity. However, since large numbers of $\alpha 6^{*}$-nAChRs are expressed on DA neuronal terminals in the NAc, inhibition of these $\alpha 6^{\star}$-nAChRs by cocaine may reduce DA release in NAc. This idea is supported by previous data that cocaine reduced DA release in the NAc (AcevedoRodriguez et al., 2014). Our results suggest that $\alpha 6^{*}$-nAChRs in the midbrain may play a critical role in the control of mesolimbic signaling strength during cocaine exposure. Thus, the cocaineinduced modulations on $\alpha 6^{*}$-nAChRs may be involved in cocaine reward and addiction process.
We realize a limitation of this study, as discussed above, is that our heterologously expressed $\alpha 6^{*}$-nAChRs are not wild-type $\alpha 6$ subunits, but are $\alpha 6$ and $\alpha 3$ subunit chimeras. Since no wild-type $\alpha 6$ subunits combined with $\beta$ subunits can form functional nAChRs, the $\alpha 6 / \alpha 3$ chimeras with $\beta 2 \beta 3$ formed functional $\alpha 6^{*}$-nAChR is only our choice to evaluate cocaine's effect on these receptor types. Although we have demonstrated that these expressed $\alpha 6^{*}$-nAChRs are representative of $\alpha 6^{*}$-nAChR function and pharmacology (Chen et al., 2018) and have been used for new drug screening (Breining et al., 2012), this study cannot precisely confirm the acting site of cocaine on $\alpha 6^{*}$-nAChRs. To overcome this weakness, we designed two experiments. First, we confirm that cocaine inhibits $\alpha 6^{*}$-nAChR function through extracellular but not intracellular site since the internal application of cocaine failed to show any inhibitory effect (Figure 4). Second, we examined cocaine's effects on the $\alpha 6_{\mathrm{M} 211 \mathrm{~L}} \alpha 3_{\mathrm{IC}} \beta 2 \beta 3-\mathrm{nAChR}$ expressed in Xenopus oocytes. Since $\alpha 6_{\mathrm{M} 211 \mathrm{~L}} \alpha 3_{\mathrm{IC}} \beta 2 \beta 3-\mathrm{nAChR}$ contains more $\alpha 6$ subunit components including the $\mathrm{N}$-terminal and all four transmembrane domains, but with $\alpha 3$ second internal loop and with a point mutation (e.g., M211 L), we compared cocaine inhibition in $\alpha 6 \mathrm{~N} \alpha 3 \mathrm{C} \beta 2 \beta 3-\mathrm{nAChR}$ - and $\alpha 6_{\mathrm{M} 211 \mathrm{~L}} \alpha 3_{\mathrm{IC}} \beta 2 \beta 3-\mathrm{nAChR}$-mediated currents. We found that cocaine equally inhibits these two types of $\alpha 6^{*}$-nAChRs (Figure 5). Furthermore, we employed a cocaine docking homology model of $\alpha 6_{\mathrm{M} 211 \mathrm{~L}} \alpha 3_{\mathrm{IC}} \beta 2 \beta 3-\mathrm{nAChR}$ with ICM Pro 1.7 software (see Methods for detail). The docking conformation with the lowest energy was used for presentation. Results show that cocaine docks to a potential binding pocket identified by the software in the subunit interface between $\alpha 6_{\mathrm{M} 211 \mathrm{~L}} \alpha 3_{\mathrm{IC}}$ and $\beta 2$ subunits and the coupling region between the $\mathrm{N}$-terminal domain and transmembrane domain (Figure 8).

The location of the predicted cocaine binding site by our docking is consistent with a noncompetitive antagonist mechanism. Since the channel activation involves an expansion in the coupling region and extracellular end of the transmembrane domain (Sauguet et al., 2014), cocaine binding in the subunit interface of the nicotinic receptor would prevent the similar expansion and antagonize the receptor. This is in contrast to the cocaine binding to the orthosteric ligand binding pocket found in the crystal structure of AChBP (Hansen and Taylor, 2007). Although they suggested non-alpha subunit interface for the noncompetitive antagonists, the ligands for the allosteric site for benzodiazepines in $\mathrm{GABA}_{\mathrm{A}}$ receptors (equivalent site for non-alpha subunit interface for nicotinic receptor) has never been found to noncompetitively antagonize the receptor. Thus, the ligand binding to that site could be a negative allosteric modulator. A noncompetitive antagonist binding site could be located within the channel pore. However, nonuse dependence of the cocaine inhibition we observed here does not support that mechanism either. Thus, cocaine likely binds to the coupling region between two subunits and prevents them from moving apart for channel opening. Validation and mapping of the competed binding pocket of cocaine in this channel is awaiting future experiments with single point mutations along with substituted cysteine accessibility methods. 


\section{AUTHOR CONTRIBUTIONS}

DC performed some patch-clamp recordings, analysis and interpretation, and the figures making. FG contributed in acquisition of patch-clamp recording data, analysis and interpretation, and the figures making. XM performed some patch-clamp recordings, analysis and interpretation. JE contributed in SH-EP1 cells cultures. YH and ZM performed some patchclamp recordings. MG performed some patch-clamp recordings and data analysis. YC contributed in study design, acquisition of the electrophysiology data recorded from oocytes, and writing a part of the manuscript. TD-G contributed in data analysis and assistance of paper writing. JN contributed in study concept and design, and revised manuscript. PW and QS contributed in study design, interpretation of data, and revising the manuscript.

\section{REFERENCES}

Acevedo-Rodriguez, A., Zhang, L., Zhou, F., Gong, S., Gu, H., De Biasi, M., et al. (2014). Cocaine inhibition of nicotinic acetylcholine receptors influences dopamine release. Front. Synaptic Neurosci. 6:19. doi: 10.3389/fnsyn.2014.00019

Akaike, N., and Moorhouse, A. J. (2003). Techniques: applications of the nervebouton preparation in neuropharmacology. Trends Pharmacol. Sci. 24, 44-47. doi: 10.1016/S0165-6147(02)00010-X

Azam, L., Winzer-Serhan, U. H., Chen, Y., and Leslie, F. M. (2002). Expression of neuronal nicotinic acetylcholine receptor subunit mRNAs within midbrain dopamine neurons. J. Comp. Neurol. 444, 260-274. doi: 10.1002/cne.10138

Blokhina, E. A., Kashkin, V. A., Zvartau, E. E., Danysz, W., and Bespalov, A. Y. (2005). Effects of nicotinic and NMDA receptor channel blockers on intravenous cocaine and nicotine self-administration in mice. Eur. Neuropsychopharmacol. 15, 219-225. doi: 10.1016/j.euroneuro.2004.07.005

Bodmer, M., Enzler, F., Liakoni, E., Bruggisser, M., and Liechti, M. E. (2014). Acute cocaine-related health problems in patients presenting to an urban emergency department in Switzerland: a case series. BMC Res. Notes 7:173. doi: 10.1186/1756-0500-7-173

Breining, S. R., Melvin, M., Bhatti, B. S., Byrd, G. D., Kiser, M. N., Hepler, C. D., et al. (2012). Structure-activity studies of 7-heteroaryl-3-azabicyclo[3.3.1] non-6-enes: a novel class of highly potent nicotinic receptor ligands. J. Med. Chem. 55, 9929-9945. doi: 10.1021/jm3011299

Cagienard, F., Schulzki, T., and Reinhart, W. H. (2014). Cocaine in high concentrations inhibits platelet aggregation in vitro. Clin. Hemorheol. Microcirc. 57, 385-394. doi: 10.3233/CH-131795

Champtiaux, N., Kalivas, P. W., and Bardo, M. T. (2006). Contribution of dihydro-beta-erythroidine sensitive nicotinic acetylcholine receptors in the ventral tegmental area to cocaine-induced behavioral sensitization in rats. Behav. Brain Res. 168, 120-126. doi: 10.1016/j.bbr.2005.10.017

Chen, D. J., Gao, F. F., Ma, X. K., Shi, G. G., Huang, Y. B., Su, Q. X., et al. (2018). Pharmacological and functional comparisons of alpha6/alpha3beta2beta3-nAChRs and alpha4beta2-nAChRs heterologously expressed in the human epithelial SHEP1 cell line. Acta Pharmacol. Sin. 39, 1571-1581. doi: 10.1038/aps.2017.209

Creed, M., Kaufling, J., Fois, G. R., Jalabert, M., Yuan, T., Luscher, C., et al. (2016). Cocaine exposure enhances the activity of ventral tegmental area dopamine neurons via calcium-impermeable NMDARs. J. Neurosci. 36, 10759-10768. doi: 10.1523/JNEUROSCI.1703-16.2016

Crunelle, C. L., Miller, M. L., Booij, J., and Van Den Brink, W. (2010). The nicotinic acetylcholine receptor partial agonist varenicline and the treatment of drug dependence: a review. Eur. Neuropsychopharmacol. 20, 69-79. doi: 10.1016/j.euroneuro.2009.11.001

Damaj, M. I., Slemmer, J. E., Carroll, F. I., and Martin, B. R. (1999). Pharmacological characterization of nicotine's interaction with cocaine and cocaine analogs. J. Pharmacol. Exp. Ther. 289, 1229-1236.

Drenan, R. M., Grady, S. R., Whiteaker, P., Mcclure-Begley, T., Mckinney, S., Miwa, J. M., et al. (2008). In vivo activation of midbrain dopamine neurons
JW contributed in study concept and design, acquisition of electrophysiology data, analysis and interpretation, statistical analysis, drafting and revising the manuscript.

\section{FUNDING}

This work was partially supported by NIDA R01 grant DA011064.

\section{ACKNOWLEDGMENTS}

The authors thank Dr. Lukas for his critical discussion and useful suggestions for writing this paper and Harrison Stratton, PhD candidate, for editing the final manuscript.

via sensitized, high-affinity alpha 6 nicotinic acetylcholine receptors. Neuron 60, 123-136. doi: 10.1016/j.neuron.2008.09.009

Einhorn, L. C., Johansen, P. A., and White, F. J. (1988). Electrophysiological effects of cocaine in the mesoaccumbens dopamine system: studies in the ventral tegmental area. J. Neurosci. 8, 100-112. doi: 10.1523/JNEUROSCI.08-01-00100.1988

Engle, S. E., Shih, P. Y., Mcintosh, J. M., and Drenan, R. M. (2013). alpha4alpha6beta2* nicotinic acetylcholine receptor activation on ventral tegmental area dopamine neurons is sufficient to stimulate a depolarizing conductance and enhance surface AMPA receptor function. Mol. Pharmacol. 84, 393-406. doi: 10.1124/mol.113.087346

Francis, M. M., Vazquez, R. W., Papke, R. L., and Oswald, R. E. (2000). Subtype-selective inhibition of neuronal nicotinic acetylcholine receptors by cocaine is determined by the alpha4 and beta4 subunits. Mol. Pharmacol. 58, 109-119. doi: 10.1124/mol.58.1.109

Gao, M., Jin, Y., Yang, K., Zhang, D., Lukas, R. J., and Wu, J. (2010). Mechanisms involved in systemic nicotine-induced glutamatergic synaptic plasticity on dopamine neurons in the ventral tegmental area. J. Neurosci. 30, 13814-13825. doi: 10.1523/JNEUROSCI.1943-10.2010

Gould, R. W., Czoty, P. W., Nader, S. H., and Nader, M. A. (2011). Effects of varenicline on the reinforcing and discriminative stimulus effects of cocaine in rhesus monkeys. J. Pharmacol. Exp. Ther. 339, 678-686. doi: 10.1124/jpet.111.185538

Hansen, S. B., and Taylor, P. (2007). Galanthamine and non-competitive inhibitor binding to ACh-binding protein: evidence for a binding site on non-alphasubunit interfaces of heteromeric neuronal nicotinic receptors. J. Mol. Biol. 369, 895-901. doi: 10.1016/j.jmb.2007.03.067

Jones, S. R., Garris, P. A., and Wightman, R. M. (1995). Different effects of cocaine and nomifensine on dopamine uptake in the caudate-putamen and nucleus accumbens. J. Pharmacol. Exp. Ther. 274, 396-403.

Klink, R., De Kerchove D'exaerde, A., Zoli, M., and Changeux, J. P. (2001). Molecular and physiological diversity of nicotinic acetylcholine receptors in the midbrain dopaminergic nuclei. J. Neurosci. 21, 1452-1463. doi: 10.1523/ JNEUROSCI.21-05-01452.2001

Koeltzow, T. E., and White, F. J. (2003). Behavioral depression during cocaine withdrawal is associated with decreased spontaneous activity of ventral tegmental area dopamine neurons. Behav. Neurosci. 117, 860-865. doi: 10.1037/0735-7044.117.4.860

Kuryatov, A., Olale, F., Cooper, J., Choi, C., and Lindstrom, J. (2000). Human alpha6 AChR subtypes: subunit composition, assembly, and pharmacological responses. Neuropharmacology 39, 2570-2590. doi: 10.1016/S0028-3908(00)00144-1

Levin, E. D., Rezvani, A. H., Wells, C., Slade, S., Yenugonda, V. M., Liu, Y., et al. (2018). alpha4beta2 Nicotinic receptor desensitizing compounds can decrease self-administration of cocaine and methamphetamine in rats. Eur. J. Pharmacol. doi: 10.1016/j.ejphar.2018.12.010

Levine, A., Huang, Y., Drisaldi, B., Griffin, E. A. Jr., Pollak, D. D., Xu, S., et al. (2011). Molecular mechanism for a gateway drug: epigenetic changes initiated by nicotine prime gene expression by cocaine. Sci. Transl. Med. 3:107ra109. doi: 10.1126/scitranslmed.3003062 
Ley, C. K., Kuryatov, A., Wang, J., and Lindstrom, J. M. (2014). Efficient expression of functional (alpha6beta2)2beta3 AChRs in Xenopus oocytes from free subunits using slightly modified alpha6 subunits. PLoS One 9:e103244. doi: 10.1371/journal.pone.0103244

Li, Q., Kong, X., Xiao, Z., Zhang, L., Wang, F., Zhang, H., et al. (2012). Structural determinants of imidacloprid-based nicotinic acetylcholine receptor inhibitors identified using 3D-QSAR, docking and molecular dynamics. J. Mol. Model. 18, 2279-2289. doi: 10.1007/s00894-011-1293-Z

Mello, N. K., Fivel, P. A., Kohut, S. J., and Carroll, F. I. (2014). Effects of chronic varenicline treatment on nicotine, cocaine, and concurrent nicotine + cocaine self-administration. Neuropsychopharmacology 39, 1222-1231. doi: 10.1038/npp.2013.325

Mello, N. K., and Newman, J. L. (2011). Discriminative and reinforcing stimulus effects of nicotine, cocaine, and cocaine + nicotine combinations in rhesus monkeys. Exp. Clin. Psychopharmacol. 19, 203-214. doi: 10.1037/a0023373

Moorman, P. G., Havrilesky, L. J., Gierisch, J. M., Coeytaux, R. R., Lowery, W. J., Peragallo Urrutia, R., et al. (2013). Oral contraceptives and risk of ovarian cancer and breast cancer among high-risk women: a systematic review and meta-analysis. J. Clin. Oncol. 31, 4188-4198. doi: 10.1200/ JCO.2013.48.9021

Nasif, F. J., Hu, X. T., and White, F. J. (2005). Repeated cocaine administration increases voltage-sensitive calcium currents in response to membrane depolarization in medial prefrontal cortex pyramidal neurons. J. Neurosci. 25, 3674-3679. doi: 10.1523/JNEUROSCI.0010-05.2005

Nnadi, C. U., Mimiko, O. A., Mccurtis, H. L., and Cadet, J. L. (2005). Neuropsychiatric effects of cocaine use disorders. J. Natl. Med. Assoc. 97, 1504-1515.

Reed, S. C., and Izenwasser, S. (2017). Nicotine produces long-term increases in cocaine reinforcement in adolescent but not adult rats. Brain Res. 1654, 165-170. doi: 10.1016/j.brainres.2016.07.044

Ritz, M. C., Lamb, R. J., Goldberg, S. R., and Kuhar, M. J. (1987). Cocaine receptors on dopamine transporters are related to self-administration of cocaine. Science 237, 1219-1223. doi: 10.1126/science.2820058

Saal, D., Dong, Y., Bonci, A., and Malenka, R. C. (2003). Drugs of abuse and stress trigger a common synaptic adaptation in dopamine neurons. Neuron 37, 577-582. doi: 10.1016/S0896-6273(03)00021-7

Sanjakdar, S. S., Maldoon, P. P., Marks, M. J., Brunzell, D. H., Maskos, U., Mcintosh, J. M., et al. (2015). Differential roles of alpha6beta $2^{*}$ and alpha4beta2* neuronal nicotinic receptors in nicotine- and cocaine-conditioned reward in mice. Neuropsychopharmacology 40, 350-360. doi: 10.1038/npp.2014.177

Sauguet, L., Shahsavar, A., Poitevin, F., Huon, C., Menny, A., Nemecz, A., et al. (2014). Crystal structures of a pentameric ligand-gated ion channel provide a mechanism for activation. Proc. Natl. Acad. Sci. U.S.A. 111, 966-971.

Schoffelmeer, A. N., De Vries, T. J., Wardeh, G., Van De Ven, H. W., and Vanderschuren, L. J. (2002). Psychostimulant-induced behavioral sensitization depends on nicotinic receptor activation. J. Neurosci. 22, 3269-3276. doi: 10.1523/JNEUROSCI.22-08-03269.2002

Sershen, H., Hashim, A., and Lajtha, A. (2010). Differences between nicotine and cocaine-induced conditioned place preferences. Brain Res. Bull. 81, 120-124. doi: 10.1016/j.brainresbull.2009.07.015

Sharma, H. S., Menon, P., Lafuente, J. V., Muresanu, D. F., Tian, Z. R., Patnaik, R., et al. (2014). Development of in vivo drug-induced neurotoxicity models. Expert Opin. Drug Metab. Toxicol. 10, 1637-1661. doi: 10.1517/17425255.2014.970168

Shytle, R. D., Silver, A. A., Wilkinson, B. J., and Sanberg, P. R. (2002). A pilot controlled trial of transdermal nicotine in the treatment of attention deficit hyperactivity disorder. World J. Biol. Psychiatry 3, 150-155.

Sordo, L., Indave, B. I., Barrio, G., Degenhardt, L., De La Fuente, L., and Bravo, M. J. (2014). Cocaine use and risk of stroke: a systematic review. Drug Alcohol Depend. 142, 1-13. doi: 10.1016/j.drugalcdep.2014.06.041

Steffensen, S. C., Shin, S. I., Nelson, A. C., Pistorius, S. S., Williams, S. B., Woodward, T. J., et al. (2018). alpha6 subunit-containing nicotinic receptors mediate low-dose ethanol effects on ventral tegmental area neurons and ethanol reward. Addict. Biol. 23, 1079-1093. doi: 10.1111/adb.12559
Wang, L., Shang, S., Kang, X., Teng, S., Zhu, F., Liu, B., et al. (2014). Modulation of dopamine release in the striatum by physiologically relevant levels of nicotine. Nat. Commun. 5:3925.

Williams, M. J., and Adinoff, B. (2008). The role of acetylcholine in cocaine addiction. Neuropsychopharmacology 33, 1779-1797. doi: 10.1038/sj. npp. 1301585

Wu, J., Kuo, Y. P., George, A. A., Xu, L., Hu, J., and Lukas, R. J. (2004). beta-Amyloid directly inhibits human alpha4beta2-nicotinic acetylcholine receptors heterologously expressed in human SH-EP1 cells. J. Biol. Chem. 279, 37842-37851. doi: 10.1074/jbc.M400335200

Wu, J., Liu, Q., Yu, K., Hu, J., Kuo, Y. P., Segerberg, M., et al. (2006). Roles of nicotinic acetylcholine receptor beta subunits in function of human alpha4-containing nicotinic receptors. J. Physiol. 576, 103-118. doi: 10.1113/ jphysiol.2006.114645

Wu, J., and Lukas, R. J. (2011). Naturally-expressed nicotinic acetylcholine receptor subtypes. Biochem. Pharmacol. 82, 800-807. doi: 10.1016/j.bcp.2011.07.067

Xiao, C., Yang, K. C., Zhou, C. Y., Jin, G. Z., Wu, J., and Ye, J. H. (2009). Nicotine modulates GABAergic transmission to dopaminergic neurons in substantia nigra pars compacta. Acta Pharmacol. Sin. 30, 851-858. doi: 10.1038/aps.2009.65

Xu, X. J., Roberts, D., Zhu, G. N., and Chang, Y. C. (2016). Competitive antagonists facilitate the recovery from desensitization of alpha1beta2gamma2 GABAA receptors expressed in Xenopus oocytes. Acta Pharmacol. Sin. 37, 1020-1030. doi: 10.1038/aps.2016.50

Yang, K., Buhlman, L., Khan, G. M., Nichols, R. A., Jin, G., Mcintosh, J. M., et al. (2011). Functional nicotinic acetylcholine receptors containing alpha6 subunits are on GABAergic neuronal boutons adherent to ventral tegmental area dopamine neurons. J. Neurosci. 31, 2537-2548. doi: 10.1523/ JNEUROSCI.3003-10.2011

Yang, K., Hu, J., Lucero, L., Liu, Q., Zheng, C., Zhen, X., et al. (2009a). Distinctive nicotinic acetylcholine receptor functional phenotypes of rat ventral tegmental area dopaminergic neurons. J. Physiol. 587, 345-361.

Yang, K. C., Jin, G. Z., and Wu, J. (2009b). Mysterious alpha6-containing nAChRs: function, pharmacology, and pathophysiology. Acta Pharmacol. Sin. 30, 740-751.

Yu, K. D., Liu, Q., Wu, J., and Lukas, R. J. (2009). Kinetics of desensitization and recovery from desensitization for human alpha4beta2-nicotinic acetylcholine receptors stably expressed in SH-EP1 cells. Acta Pharmacol. Sin. 30, 805-817. doi: 10.1038/aps.2009.48

Zachariou, V., Caldarone, B. J., Weathers-Lowin, A., George, T. P., Elsworth, J. D., Roth, R. H., et al. (2001). Nicotine receptor inactivation decreases sensitivity to cocaine. Neuropsychopharmacology 24, 576-589. doi: 10.1016/ S0893-133X(00)00224-4

Zanetti, L., Picciotto, M. R., and Zoli, M. (2007). Differential effects of nicotinic antagonists perfused into the nucleus accumbens or the ventral tegmental area on cocaine-induced dopamine release in the nucleus accumbens of mice. Psychopharmacology 190, 189-199. doi: 10.1007/s00213-006-0598-6

Zhang, X. F., Cooper, D. C., and White, F. J. (2002). Repeated cocaine treatment decreases whole-cell calcium current in rat nucleus accumbens neurons. J. Pharmacol. Exp. Ther. 301, 1119-1125. doi: 10.1124/jpet.301.3.1119

Zhang, X. F., Hu, X. T., and White, F. J. (1998). Whole-cell plasticity in cocaine withdrawal: reduced sodium currents in nucleus accumbens neurons. J. Neurosci. 18, 488-498. doi: 10.1523/JNEUROSCI.18-01-00488.1998

Conflict of Interest Statement: The authors declare that the research was conducted in the absence of any commercial or financial relationships that could be construed as a potential conflict of interest.

Copyright (C) 2019 Chen, Gao, Ma, Eaton, Huang, Gao, Chang, Ma, Der-Ghazarian, Neisewander, Whiteaker, Wu and Su. This is an open-access article distributed under the terms of the Creative Commons Attribution License (CC BY). The use, distribution or reproduction in other forums is permitted, provided the original author(s) and the copyright owner(s) are credited and that the original publication in this journal is cited, in accordance with accepted academic practice. No use, distribution or reproduction is permitted which does not comply with these terms. 